\title{
Effect of Regular Yogic Training on Growth Hormone and Dehydroepiandrosterone Sulfate as an Endocrine Marker of Aging
}

\author{
Sridip Chatterjee ${ }^{1}$ and Samiran Mondal $^{2}$ \\ ${ }^{1}$ Department of Physical Education, Jadavpur University, Kolkata, West Bengal 700032, India \\ ${ }^{2}$ Department of Physical Education, Vinaya Bhavana, Visva Bharati, Santiniketan, West Bengal 731235, India \\ Correspondence should be addressed to Sridip Chatterjee; sridipphd14@gmail.com and \\ Samiran Mondal; msamiran@rediffmail.com
}

Received 15 November 2013; Revised 17 February 2014; Accepted 18 February 2014; Published 8 May 2014

Academic Editor: Vernon A. Barnes

Copyright (c) 2014 S. Chatterjee and S. Mondal. This is an open access article distributed under the Creative Commons Attribution License, which permits unrestricted use, distribution, and reproduction in any medium, provided the original work is properly cited.

Growth hormone (GH) and dehydroepiandrosterone sulfate (DHEAS) secretion decline with advancing age and are associated with the symptoms of aging. Yogic texts claimed that regular practice of yoga may restore and maintain general endocrinological properties in the human body. Objective of the Study. To observe the effect of yogic training for twelve weeks on basal level of GH and DHEAS in middle aged group. Method. Forty-five untrained volunteers were divided into two groups, that is, yoga practicing (experimental: male 15, age $42.80 \pm 7.43$ yrs; female 8 , age $44.75 \pm 8.40 \mathrm{yrs)}$ ) and waitlisted control group (male 15 , age $41.67 \pm 7.87 \mathrm{yrs;}$ female 7 , age $45.43 \pm 7.00 \mathrm{yrs}$ ). The experimental group underwent combined yogic practices daily in the morning for 6 days/week for 12 weeks, whereas control group continued their usual routine activities. Standing height, body weight, body mass index, and basal level of GH and DHEAS were measured before commencement and after six and twelve weeks of yogic training period. The repeated measure ANOVA was used for data analysis. Results. 12 weeks of yogic training produces a significant increase in GH and DHEAS for both male and female groups as compared to their baseline data, whereas no as such changes were observed in the control group. Conclusion. Combined approach of graded yogic training may be beneficial for maintaining the basal level of GH and DHEAS in the human body, thus promoting healthy aging.

\section{Introduction}

Human growth hormone (GH) secreted from anterior pituitary has important roles in growth of almost all tissues, metabolism, and changes in body composition [1-3]. Dehydroepiandrosterone sulfate (DHEAS), secreted by the adrenal cortex, acts in the human body as a neurosteroid, cardioprotective, antidiabetic, antiobesity, and immunoenhancing agent. It is also reported as youth hormone [4-6].

Basal level of GH and DHEAS declines with advancing age and is reported as antiaging hormones [7-11]. Nonpharmachological replacement of these hormones by natural stimulus like yoga may be a strategy for delaying the onset of aging [11]. GH and DHEAS showed a slower decline in active individual than the inactive peers [4]. Regular exercise habit induces the secretion pattern of GH and DHEAS throughout the lifespan [12-16].

It is reported in the ancient yogic texts that regular practice of yoga may delay aging process [17-23]. All traditional schools of yoga advocate a movement towards perfection of the body, perfection of the mind, or that of both. Today yoga is popular not so much as a system of philosophy but as a system of practical discipline to improve physical, physiological, psychological, and spiritual health [24-29]. Researches on $\mathrm{GH}$, DHEAS, and yogic training in the perspective of aging are very few.

Jevning et al. [30] studied plasma prolactin and growth hormone before, during, and after transcendental meditation (TM) and found that GH concentration was unchanged in both TM and rest group. In another study, changes in baseline 
levels and responses to laboratory stressors were examined for growth hormone before and after 4 months of either the TM technique or a stress education control condition. Growth hormone increased after 4 months of TM meditation in response to laboratory stressors [31]. Plasma levels of growth hormone concentrations fell slightly (insignificant) in experienced meditators and nonmeditators groups during and after meditation/relaxation period, the trend being more apparent in meditators [32]. The long-term practice of TM and TM Sidhi Programme for consecutive weeks (initial and after 5, 49, 115, and 167 weeks) showed a progressive insignificant decrease of growth hormone [33]. Schell et al. [34] reported that there was no substantial growth hormone difference between yoga practice group and control group. Dehydroepiandrosterone sulfate (DHEAS) was measured in 270 male and 153 women who were experienced practitioners of the TM and TM Sidhi Programme. The mean DHEAS levels were found higher in all the age groups compared with age-sex matched nonmeditators [35]. Long-term combined practice of yoga (asana, pranayama, and meditation) produces an insignificant increase of DHEAS level compared to control group [36].

Most of the above mentioned researches were mainly conducted to observe the effect of yoga on single intervention (meditation) except the study of Vera et al. [36]. The principle of "Holistic approach of Yogic Science," that is, the body as an integrated (whole) matter rather than a series of systems, has been considered in the present study. Yogic practice will also be useful if the intensity and duration of the training are maintained properly.

Therefore, in this study, the researcher attempted to observe the combined effect of regular graded yogic training for twelve weeks on basal level of GH and DHEAS in middle aged group.

\section{Materials and Methods}

2.1. Study Location. The present study was carried out in the Department of Physical Education, Visva-Bharati University, Santiniketan, Birbhum, West Bengal, India.

2.2. Subjects. A "Yoga Awareness Camp" was organized jointly by the researcher and one of the renowned community health clubs in Bolpur (Santiniketan) Municipality area for collection of data. Fifty middle aged male and female willingly registered their names to attend this yoga camp. Fortyfive healthy middle aged persons were able to meet the screening criteria. Subjects' age range was between 35 and 55 years, belonging to almost the same socioeconomical background. They were recreationally active but not specifically acquainted with the yogic practices before. Five subjects were excluded from the study due to major injury or illness. Subjects were free to withdraw themselves from the training at any point during the study (Figure 1).

2.3. Study Design. In the present study the convenient sampling method was adopted because there were some couples who were willing to volunteer themselves in this study if they got the opportunity to practice together. Considering their requests, the subjects were divided on the first come first serve basis. So, according to the serial of the registration, 23 (male 15 , age $42.80 \pm 7.42 \mathrm{yrs}$; female 8 , age $44.75 \pm 8.40$ yrs) middle aged healthy volunteers served as experimental group and 22 (male 15, age $41.67 \pm 7.87 \mathrm{yrs}$; female 7 , age $45.43 \pm 7.00 \mathrm{yrs}$ ) age-sex matched subjects were in the waitlisted control group. The experimental group underwent yogic practices, whereas waitlisted control group maintained usual routine activities. To meet the purpose of the study, both the experimental and waitlisted control group subjects were assessed at baseline (pretest), after six weeks (midtest) and twelve weeks (posttest) accordingly. The "Board of Studies," Department of Physical Education, Visva-Bharati University, went through the whole procedure of this study and forwarded this to the institutional (university) research board. Finally, the university research board approved the study. The aims and objectives of this study were thoroughly discussed with all the subjects, and then a standard informed consent forms were signed by the subjects.

2.4. Assessments. Chronological age, standing height, body Weight, body mass index (BMI), basal level of plasma growth hormone $(\mathrm{GH})$, and dehydroepiandrosterone sulfate (DHEAS) were measured for this study. All the data were collected according to the guidelines of standard scientific manual. Instruments were calibrated every day before the experiment and standard procedural steps were followed. The extreme scores (highest and lowest), if any, were discarded.

2.5. Hormonal Assay. Basal level of GH and DHEAS was measured by enzyme-linked immunosorbent assay method (ELISA).

Specimen Collection and Preparation. Following an overnight (12 hrs) fasting, venues blood samples were taken via a disposable plastic syringe inserted into an antecubital forearm vein. Blood $(5 \mathrm{~mL})$ was allotted to colt for one hour in a plain test-tube (Burocell) and then centrifuged (REMI) at $30^{\circ} \mathrm{C}$ for 5 minutes at $6000 \mathrm{Rev} \mathrm{min}^{-1}$ to separate the serum from the cells. Before proceeding with the ELISA test, (Monobind Inc., Lake Forest, CA 92630, USA) reagent (GH, Product Code: 1725-300; DHEAS, Product Code: 5125-300) and specimen serum were brought to room temperature $\left(20-27^{\circ} \mathrm{C}\right)$.

GH Assay. Reagent preparation: wash Buffer: $0.300 \mathrm{~mL}$ wash buffer was mixed with $1000 \mathrm{~mL}$ distilled water and kept at room temperature $\left(20-27^{\circ} \mathrm{C}\right)$. Working substrate solution: the contents of the amber vial labeled solution " $\mathrm{A}$ " poured into the clear vial labeled solution "B," mixed and labeled accordingly and stored at $2-8^{\circ} \mathrm{C}$. Test Procedure: formatting the microplates' wells for each serum reference. $0.05 \mathrm{~mL}$ specimen serum was taken by the pipette $(0-50 \mathrm{~mL})$ and given into the assigned wells. $0.100 \mathrm{~mL}$ enzyme reagent solution was added to all wells and swirl the microplate gently for 20-30 seconds to mix and then incubated for 60 minutes at room temperature. Manually wash the microwells by the prepared wash buffer for three times and dry them 


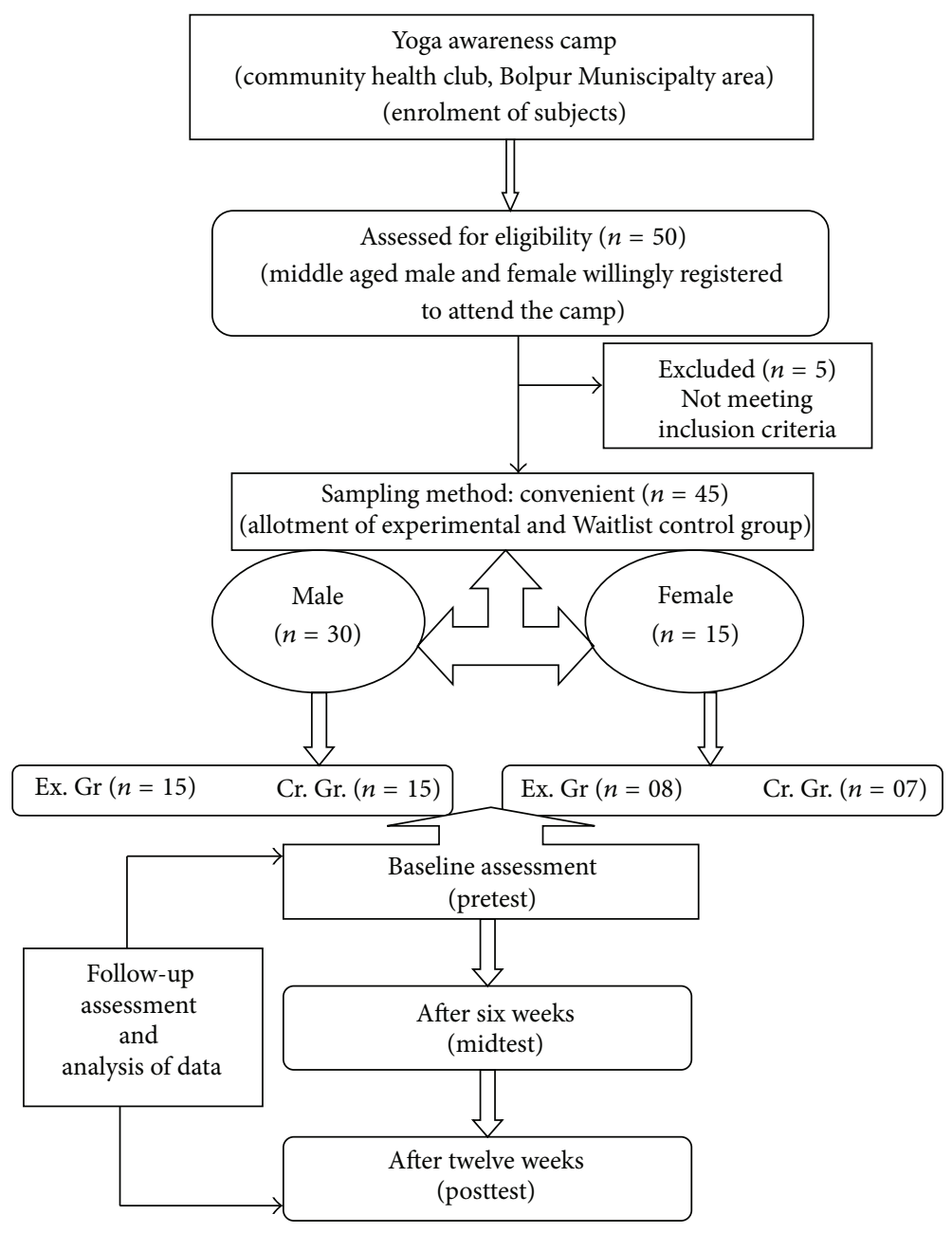

FIgure 1: Trial profile.

with tissue paper. After that $0.100 \mathrm{~mL}$ substrate solution was add to all wells and incubated $\left(20-27^{\circ} \mathrm{C}\right)$ for 15 minutes. Reagents were added in the same order to minimize reaction time differences between wells. Immediately after that, add $0.050 \mathrm{~mL}$ of stop solution to each well and gently mix it for $15-$ 20 seconds. Recording of results: the microplates were passed under the ELISA reader machine and results were recorded in ng/mL.(Manual, Monobind Inc. Lake Forest, CA 92630, USA).

DHEAS Assay. Reagent preparation: wash Buffer: $0.300 \mathrm{~mL}$ wash buffer was mixed with $1000 \mathrm{~mL}$ distilled water and kept at room temperature $\left(20-27^{\circ} \mathrm{C}\right)$. Working substrate solution: the contents of the amber vial labeled solution " $\mathrm{A}$ " poured into the clear vial labeled solution "B," mixed and labeled accordingly and stored at $2-8^{\circ} \mathrm{C}$. Test procedure: formatting the microplates' wells for each serum reference. $0.010 \mathrm{~mL}$ specimen serum was taken by the pipette $(0-50 \mathrm{~mL})$ and given into the assigned wells. $0.100 \mathrm{~mL}$ enzyme reagent solution was added to all wells and swirl the microplate gently for 20-30 seconds to mix. Anti-DHEAS biotin reagent should be added to all wells and swirl the microplate again for 20-30 seconds to mix and finally incubate for 30 minutes at room temperature. Manually wash the microwells by the prepared wash buffer for three times and dry them with tissue paper. After that $0.100 \mathrm{~mL}$ substrate solution was add to all wells and incubated $\left(20-27^{\circ} \mathrm{C}\right)$ for 15 minutes. Reagents were added in the same order to minimize reaction time differences between wells. Immediately after that, add $0.050 \mathrm{~mL}$ of stop solution to each well and gently mix it for 15-20 seconds. Recording of results: the microplates were passed under the ELISA reader machine and results were recorded in $\mathrm{ng} / \mathrm{mL}$. (Manual, Monobind Inc. Lake Forest, CA 92630, USA).

2.6. Training Protocol. The yoga training protocol was formulated according to the health and physical ability of the subjects. The yoga intervention consisted of Suryanamaskara (sun salutation) or Shithilikarana (loosening) practices, Kriyas (cleansing process), Asanas (static and dynamic postures), Pranayamas (breathing practices), and Dhyana (meditation). Detailed yogic practices are scheduled according to the demand of the yogic science and to fulfill the objectives of the study. Progressive training load method [37] was applied in the form of duration, repetitions, and volume from 1st week to the end of the training (twelve weeks) 
TABLE 1: Detailed yogic practice protocol for 1st week (45 minute-schedule).

\begin{tabular}{|c|c|c|c|c|}
\hline Name of yogic practices & Execution time/intensity & Repetitions/frequency & Recovery time/density & Total time/volume \\
\hline $\begin{array}{l}\text { Suryanamaskar (12 counts): } \\
\text { (1) Pranamasana, (2) Hasta } \\
\text { Uttanasana, (3) } \\
\text { Padahastasana, (4) Aswa } \\
\text { Sanchalanasana, (5) } \\
\text { Parvatasana, (6) Ashtanga } \\
\text { Namaskar, (7) Bhujangasana, } \\
\text { (8) Kurmasana, (9) Tulasana, } \\
\text { (10) Aswa Sanchalanasana, } \\
\text { (11) Padahastasana, and (12) } \\
\text { Hasta Uttanasana } \\
\text { (3 days/week) } \\
\text { OR }\end{array}$ & $1.5 \times 5=7.5 \mathrm{~min}$ & 5 times & $30 \mathrm{sec} \times 5=2.5 \mathrm{~min}$ & $10 \mathrm{~min}$ \\
\hline $\begin{array}{l}\text { Shitilikarana Practices, and } \\
\text { Tadasana Practices } \\
\text { (3 days/week) }\end{array}$ & $4 \times 2=8 \mathrm{~min}$ & 2 times & $1 \times 2=2 \mathrm{~min}$ & \\
\hline Kriya: Kapalbhati & $\begin{array}{c}30 \text { strokes } \\
\text { @ } 1 \text { stroke } / \mathrm{sec}=2.5 \mathrm{~min}\end{array}$ & 5 times & $\begin{array}{l}30 \mathrm{sec} \text { rest in between each } \\
\text { round }=2.5 \mathrm{~min}\end{array}$ & $5 \mathrm{~min}$ \\
\hline $\begin{array}{l}\text { Asana: } \\
\text { Ardhahalasana, } \\
\text { Ekpadapabanmuktasana, } \\
\text { Bhujangasana, } \\
\text { Ardhasalvasana, Yogmudra, } \\
\text { Bakrasana, Janusirshasana, } \\
\text { Ardhakati Chakrasana, } \\
\text { Trikonasana, and Vadrasana }\end{array}$ & $\begin{array}{c}\text { Holding time: } 5 \mathrm{sec} \\
10 \text { Asana } \times 1.5 \mathrm{~min}=15 \mathrm{~min}\end{array}$ & 1 times & $\begin{array}{c}30 \mathrm{sec} \text { rest in between asana } \\
10 \times 30 \mathrm{sec}=5 \mathrm{~min}\end{array}$ & $20 \mathrm{~min}$ \\
\hline $\begin{array}{l}\text { Pranayama: Sectional } \\
\text { Breathing } \\
\text { (abdominal and thoracic), } \\
\text { deep breathing }\end{array}$ & 3 Pranayama $\times 2.5 \mathrm{~min}=7.5 \mathrm{~min}$ & 5 times/pranayama & $\begin{array}{c}50 \mathrm{sec} \text { rest in between } \\
\text { Pranayama, } \\
50 \mathrm{sec} \times 3=2.5 \mathrm{~min}\end{array}$ & $10 \mathrm{~min}$ \\
\hline
\end{tabular}

Total time: 45 minutes

period (Tables 1, 2, 3, 4, 5, and 6). From 8th week onward three types of practice combination were used. Each of these combinations was practiced two days in a week. There are few yogic techniques which cannot be practiced regularly, whereas another technique needs longer time to practice. So to justify the training load and maintain it accordingly the present researcher adopted this combination schedule. Waitlisted control group was given no specific intervention and continued with their routine activities. They attended "health and positive mental attitude awareness" class in a day per week. A general record book was also maintained to note their daily activity level and lifestyle. Details of the combination were as follows.

Combination 1: Kriya (cleansing process) 30 mins; Suryanamaskara (sun salutation) 10 mins; Asana (posture) 35 mins; Pranayama (breathing practices) 20 mins; and dhyana (meditation) 10 mins.

Combination 2: Suryanamaskara 10 mins; Kriya 10 mins; Asana 35 mins; Pranayama 25 mins; and dhyana for 25 mins.

Combination 3: Suryanamaskara 15 mins; Kriya 15 mins; Asana 45 mins; Pranayama 25 mins; and dhyana for 5 mins (Tables 7, 8, and 9).
2.7. Statistical Procedure. In the present study the repeated measures analysis of variance (RM ANOVA) was used for data analysis [38]. Repeated measures ANOVA are an extension of paired $t$-tests. Here, RM ANOVA was used to test for (i) significant differences between the assessments, that is, at baseline (pretest), after six weeks (midtest), and after twelve weeks (posttest), and this was a within subjects factor denoted by time and (ii) differences between the groups (experimental (yoga) and waitlist control) and this was a between subjects factor, and the test for a time by group interaction provides a global test for an intervention effect. Postdata were compared to pre- and middata of respective group using post hoc analysis with Bonferroni adjustment. The level of significance was set at 0.05 levels $(P<0.5)$. Simple percentages (\%) were also calculated from the mean value to see the quantitative changes of the yogic training. Repeated measures "Analysis of Variances" (RM ANOVA) are one in which multiple measurements on the same experimental subjects comprise the replicate data [39].

\section{Results}

3.1. Baseline Characteristics. Before commencement of the yogic training baseline difference between experimental and 
TABLE 2: Detailed yogic practice protocol for 2 nd week (50 minute-schedule).

\begin{tabular}{|c|c|c|c|c|}
\hline Name of yogic practices & Execution time & Repetitions & Recovery time & Total time \\
\hline $\begin{array}{l}\text { Suryanamaskar } \\
\text { (3 days/week) }\end{array}$ & $1.25 \times 6=7.5 \mathrm{~min}$ & 6 times & $25 \mathrm{sec} \times 6=2.5 \mathrm{~min}$ & \multirow{3}{*}{$10 \mathrm{~min}$} \\
\hline & & & & \\
\hline $\begin{array}{l}\text { Shitilikarana Practices, } \\
\text { Tadasana Practices } \\
\text { (3 days/week) }\end{array}$ & $2.84 \times 3=8.25 \mathrm{~min}$ & 3 times & $35 \mathrm{sec} \times 3=1.75 \mathrm{~min}$ & \\
\hline Kriya: Kapalbhati & 45 strokes @ 1 stroke $/ \mathrm{sec}=3.75 \mathrm{~min}$ & 5 times & $\begin{array}{l}15 \mathrm{sec} \text { rest in between each } \\
\text { round }=1.25 \mathrm{~min}\end{array}$ & $5 \mathrm{~min}$ \\
\hline $\begin{array}{l}\text { Asana: Ardhahalasana, } \\
\text { Ekpadapabanmuktasana, } \\
\text { Bhujangasana, } \\
\text { Ardhasalvasana, Yogmudra, } \\
\text { Bakrasana, Janusirshasana, } \\
\text { Lataral Chakrasana, } \\
\text { Trikonasana, and Vadrasana } \\
\end{array}$ & $\begin{array}{l}\text { Holding time: } 10 \mathrm{sec} \\
10 \text { Asana } \times 2 \mathrm{~min}=20 \mathrm{~min}\end{array}$ & 1 times & $\begin{array}{c}30 \mathrm{sec} \text { rest in between Asana } \\
10 \times 30 \mathrm{sec}=5 \mathrm{~min}\end{array}$ & $25 \mathrm{~min}$ \\
\hline $\begin{array}{l}\text { Pranayama: hand in and out } \\
\text { breathing, hand stretching } \\
\text { breathing, and ankle } \\
\text { stretching breathing }\end{array}$ & 3 Pranayama $\times 2.5 \mathrm{~min}=7.5 \mathrm{~min}$ & 5 times/Pranayama & $\begin{array}{c}50 \mathrm{sec} \text { rest in between } \\
\text { Pranayama, } \\
50 \mathrm{sec} \times 3=2.5 \mathrm{~min}\end{array}$ & $10 \mathrm{~min}$ \\
\hline \multicolumn{5}{|c|}{ Total time: 50 minutes } \\
\hline
\end{tabular}

TABLE 3: Detailed yogic practice protocol for 3rd week (60-minute schedule).

\begin{tabular}{|c|c|c|c|c|}
\hline Name of yogic practices & Execution time & Repetitions & Recovery time & Total time \\
\hline $\begin{array}{l}\text { Suryanamaskar } \\
\text { (3 days/week) } \\
\text { OR }\end{array}$ & $1.25 \times 6=7.5 \mathrm{~min}$ & 6 times & $25 \mathrm{sec} \times 6=2.5 \mathrm{~min}$ & $10 \mathrm{~min}$ \\
\hline $\begin{array}{l}\text { Shitilikarana Practices, } \\
\text { Tadasana Practices } \\
\text { (3 days/week) }\end{array}$ & $2.84 \times 3=8.25 \mathrm{~min}$ & 3 times & $35 \mathrm{sec} \times 3=1.75 \mathrm{~min}$ & \\
\hline $\begin{array}{l}\text { Kriya: } \\
\text { Kapalbhati and } \\
\text { Uddiyan }\end{array}$ & $\begin{array}{l}60 \text { strokes @ } 1 \text { stroke } / \mathrm{sec}=5 \mathrm{~min} \\
30 \mathrm{sec} \times 3=1.5 \mathrm{~min}\end{array}$ & $\begin{array}{l}5 \text { times } \\
3 \text { times }\end{array}$ & $\begin{array}{c}24 \mathrm{sec} \times 5 \text { times }=2 \mathrm{~min} \\
30 \mathrm{sec} \times 3=1.5 \mathrm{~min}\end{array}$ & $7+3=10 \mathrm{~min}$ \\
\hline $\begin{array}{l}\text { Asana: Ardhahalasana, } \\
\text { Ekpadapabanmuktasana, } \\
\text { Bhujangasana, } \\
\text { Ardhasalvasana, Yogmudra, } \\
\text { Bakrasana, Janusirshasana, } \\
\text { and Lataral }\end{array}$ & Holding time: $10 \mathrm{sec}$ & 2 times & $12 \times 15 \mathrm{sec} \times 2=6 \mathrm{~min}$ & $25 \mathrm{~min}$ \\
\hline $\begin{array}{l}\text { Chakrasana, Trikonasana, } \\
\text { Vadrasana, Matyasana, and } \\
\text { Padmasana }\end{array}$ & 12 Asana $\times 1.5 \min =18 \mathrm{~min}$ & & 1 min complete Savasana & \\
\hline $\begin{array}{l}\text { Pranayana: Suryabhedana, } \\
\text { Chandrabhedana, and } \\
\text { Anulome-vilome }\end{array}$ & 3 Pranayana $\times 3 \mathrm{~min}=9 \mathrm{~min}$ & 5 times & $\begin{array}{c}20 \mathrm{sec} \text { rest in between } \\
\text { Pranayana } \\
20 \times 3=1 \mathrm{~min}\end{array}$ & $10 \mathrm{~min}$ \\
\hline $\begin{array}{l}\text { Yogic relaxation: spinal } \\
\text { practices }\end{array}$ & $\begin{array}{c}\text { Five Variations } \\
1 \mathrm{~min} \times 5=5 \mathrm{~min}\end{array}$ & One time each & - & $5 \mathrm{~min}$ \\
\hline
\end{tabular}

control group for the selected variables was calculated (independent $t$-test) and insignificant difference was observed for both male and female group (Table 10).

General Health Variables. The body weight and BMI of experimental group (male and female) fall significantly $(P<0.001)$ after twelve weeks of graded yogic training compare to baseline where as in the control group no such changes were observed during these twelve weeks (Table 2).

3.2. Endocrinological Variables. In the present study the basal level of serum GH was increased significantly after six and twelve weeks of graded yogic training compared 
TABLE 4: Detailed yogic practice protocol for 4 th week (70-minute schedule).

\begin{tabular}{|c|c|c|c|c|}
\hline Name of yogic practices & Execution time & Repetitions & Recovery time & Total time \\
\hline Suryanamaskara & $1 \mathrm{~min} \times 8=8 \mathrm{~min}$ & 8 times & $15 \mathrm{sec} \times 8$ times $=2 \mathrm{~min}$ & $10 \mathrm{~min}$ \\
\hline $\begin{array}{l}\text { Kriya: kapalbhati } \\
\text { Uddyan and Agnisara }\end{array}$ & $\begin{array}{c}80 \text { strokes @ } 1 \text { stroke } / \mathrm{sec}=6.40 \mathrm{~min} \\
30 \mathrm{sec} \times 3 \times 2=3 \mathrm{~min}\end{array}$ & $\begin{array}{l}5 \text { times } \\
3 \text { times }\end{array}$ & $\begin{array}{c}40 \mathrm{sec} \times 5 \text { times }=3.20 \mathrm{~min} \\
20 \mathrm{sec} \times 2 \times 3=2 \mathrm{~min}\end{array}$ & $15 \mathrm{~min}$ \\
\hline $\begin{array}{l}\text { Asana: Ardhahalasana, } \\
\text { Ekpadapabanmuktasana, } \\
\text { Bhujangasana, Ardhasalvasana, } \\
\text { Yogmudra, Bakrasana, } \\
\text { Janusirshasana, Lataral } \\
\text { Chakrasana, Trikonasana, } \\
\text { Vadrasana, Matyasana, and } \\
\text { Padmasana }\end{array}$ & $\begin{array}{l}\text { Holding time: } 10 \mathrm{sec} \\
12 \text { Asana } \times 1.5 \mathrm{~min}=18 \mathrm{~min}\end{array}$ & 2 times & $\begin{array}{l}12 \times 15 \mathrm{sec} \times 2=6 \mathrm{~min} \\
1 \text { min complete Savasana }\end{array}$ & $25 \min$ \\
\hline $\begin{array}{l}\text { Pranayana: Anulome-Vilome, } \\
\text { Shitali/Shifkari, and Bhastrika }\end{array}$ & 3 Pranayana $\times 4 \mathrm{~min}=12 \mathrm{~min}$ & 5 times & $\begin{array}{c}1 \text { min deep breathing in } \\
\text { between Pranayama } \\
1 \times 3=3 \text { min }\end{array}$ & $15 \mathrm{~min}$ \\
\hline Yogic relaxation & \multicolumn{3}{|c|}{ Relaxation through Savasana } & $5 \mathrm{~min}$ \\
\hline \multicolumn{5}{|c|}{ Total time: 70 minutes } \\
\hline
\end{tabular}

TABLE 5: Detailed yogic practice protocol for 5th week (80-minute schedule).

\begin{tabular}{|c|c|c|c|c|}
\hline Name of yogic practices & Execution time & Repetitions & Recovery time & Total time \\
\hline Suryanamaskara & $1 \mathrm{~min} \times 12=12 \mathrm{~min}$ & 12 times & $15 \sec \times 12=3 \mathrm{~min}$ & $15 \mathrm{~min}$ \\
\hline Kriya: kapalbhati & 60 strokes@ 2 stroke $/ \mathrm{sec}=2.5 \mathrm{~min}$ & 5 times & $30 \mathrm{sec} \times 5$ times $=2.5 \mathrm{~min}$ & \\
\hline $\begin{array}{l}\text { Uddyan and Agnisara } \\
\text { ( } 4 \text { days/week) } \\
\text { OR }\end{array}$ & $30 \mathrm{sec} \times 3 \times 2=3 \mathrm{~min}$ & 3 times & $20 \mathrm{sec} \times 2 \times 3=2 \mathrm{~min}$ & $10 \mathrm{~min}$ \\
\hline $\begin{array}{l}\text { Jalaneti and Sutraneti } \\
2 \text { days/week }\end{array}$ & $4 \min \times 2=8 \min$ & 1 times & $1 \min \times 2=2 \min$ & \\
\hline
\end{tabular}

Asana: Uttanpadasana,

Pabanmuktasana, Naukasana,

Matyasana, Bhujangasana,

Salvasana, Naukasana (prone),

Bakrasana, Usthrasana, Vajrasana,

Holding time: $15 \mathrm{sec}$

$15 \times 1.5 \mathrm{~min}=22.5 \mathrm{~min}$

2 times

$15 \times 15 \mathrm{sec} \times 2=7.5 \mathrm{~min}$

$30 \mathrm{~min}$

Yogmudra

Pachimotthanasana, Tarasana,

Trikomasana, and Katichakrasana

\begin{tabular}{|c|c|c|c|c|}
\hline $\begin{array}{l}\text { Pranayana: } \\
\text { Anulome-vilome, Shitali/Shifkari, } \\
\text { and Bhastrika }\end{array}$ & 3 Pranayana $\times 4 \min =12 \mathrm{~min}$ & 5 times & $\begin{array}{c}1 \text { min deep breathing in } \\
\text { between Pranayama } \\
1 \times 3=3 \text { min }\end{array}$ & $15 \mathrm{~min}$ \\
\hline $\begin{array}{l}\text { Meditation: } \\
\text { A-U-M/chanting or complete Aum }\end{array}$ & Practice span: $10 \mathrm{~min}$ & $\begin{array}{l}\text { Depend upon } \\
\text { individual } \\
\text { capacity }\end{array}$ & $\begin{array}{l}\text { Complete relaxation during } \\
\text { recitation }\end{array}$ & $10 \mathrm{~min}$ \\
\hline
\end{tabular}

to baseline, whereas no such changes were observed in the waitlist control group for both male and female (Table 11). The improvements were recorded $115 \%$ after six $(P<0.001$, paired $t$-test, pretest versus midtest) and $282 \%$ after twelve weeks $(P<0.001$, paired $t$-test, pretest versus posttest) in male group as compared with the baseline value. In the female group the $\mathrm{GH}$ increased $120 \%$ after six $(P<0.001$, paired $t$-test, pretest versus midtest) and $200 \%$ after twelve weeks $(P<0.001$, paired $t$-test, pretest versus posttest) of yogic training as compared with the baseline value, whereas changes were negligible in control group during this twelve weeks (Figures 2 and 3). The ANOVA results are summarized in Table 12.

The basal level of serum DHEAS was increased significantly after six and twelve weeks of graded yogic training compared to baseline, whereas no such changes were observed in the waitlist control group for both males and females (Table 11). The improvements were recorded as $16.95 \%$ after six $(P<0.04$, paired $t$-test, pretest versus midtest $)$ and $58.67 \%(P<0.001$, paired $t$-test, pretest versus posttest) after twelve weeks in male group as compared with the baseline value. In the female group it was increased by 
TABLE 6: Detailed yogic practice protocol for 6th and 7th week (90-minute schedule).

\begin{tabular}{|c|c|c|c|c|}
\hline Name of yogic practices & Execution time & Repetitions & Recovery time & Total time \\
\hline Suryanamaskar & $40 \mathrm{sec} \times 12=8 \mathrm{~min}$ & 12 times & $10 \mathrm{sec} \times 12=2 \mathrm{~min}$ & $10 \mathrm{~min}$ \\
\hline Kriya: Kapalbhati & 80 strokes@ 2 stroke $/ \mathrm{sec}=4 \mathrm{~min}$ & 6 times & $60 \mathrm{sec} \times 6$ times $=6 \mathrm{~min}$ & \\
\hline $\begin{array}{l}\text { Uddyan and Agnisara } \\
\text { (3 days/week) }\end{array}$ & $30 \sec \times 3 \times 2=3 \mathrm{~min}$ & 3 times & $20 \sec \times 2 \times 3=2 \mathrm{~min}$ & $15 \mathrm{~min}$ \\
\hline $\begin{array}{l}\text { Jalaneti and Sutraneti } \\
\text { ( } 2 \text { days/week) }\end{array}$ & $5 \mathrm{~min} \times 2=10 \mathrm{~min}$ & 1 times & $2.5 \mathrm{~min} \times 2=5 \mathrm{~min}$ & 1 ग 11111 \\
\hline $\begin{array}{l}\text { Vaman Dauti } \\
\text { (1 day/week) }\end{array}$ & $10 \mathrm{~min}$ & 1 times & $5 \min$ & \\
\hline
\end{tabular}

Asana: Uttanpadasana,

Pabanmuktasana,

Naukasana, Matyasana,

Bhujangasana,

Salvasana, Naukasana

(prone), Bakrasana,

Holding time: $20 \mathrm{sec}$

Usthrasana, Vajrasana,

and Yogmudra

Pachimotthanasana,

Tarasana, Trikomasana, $\quad 15 \times 2 \mathrm{~min}=30 \mathrm{~min}$

and Katichakrasana

Pranayana:

Anulome-violme,

Shitali/Shitkari,

Bhastrika, and Ujjai

Meditation:

A-U-M or complete

"AUM" chanting

2 times

$10 \mathrm{sec} \times 15 \times 2=5 \mathrm{~min}$

$35 \mathrm{~min}$

4 Pranayama $\times 4 \mathrm{~min}=16 \mathrm{~min}$

Practice span: $10 \mathrm{~min}$
Depend upon individual capacity
1 min deep breathing in between Pranayama $1 \mathrm{~min} \times 4=4 \mathrm{~min}$
$20 \mathrm{~min}$

Complete relaxation during recitation

TABLE 7: Detailed yogic practice protocol for 8 th to 12 th weeks (105-minute schedule, $1.45 \mathrm{hrs)} \mathrm{combination-1} \mathrm{(2} \mathrm{days/week,} \mathrm{Monday} \mathrm{and}$ Friday).

\begin{tabular}{|c|c|c|c|c|}
\hline Name of yogic practices & $\begin{array}{l}\text { Execution } \\
\text { time }\end{array}$ & Repetitions & Recovery time & Total time \\
\hline $\begin{array}{l}\text { Kriya: } \\
\text { Jalaneti, Sutraneti, and } \\
\text { Vamandhauti }\end{array}$ & $6+6+10=25 \min$ & One & $3 \times 1 \min =3 \min$ & $25+5=30 \mathrm{~min}$ \\
\hline Kapalbhati & $\begin{array}{c}60 \text { strocks@ } 2 \text { strokc/sec }= \\
2.5 \mathrm{~min}\end{array}$ & 5 Times & $30 \mathrm{sec} \times 5$ times $=2.5 \mathrm{~min}$ & \\
\hline Suryanamaskar & $25 \mathrm{sec} \times 15=6.25 \mathrm{~min}$ & 15 Times & $15 \mathrm{sec} \times 15=3.75 \mathrm{~min}$ & $10 \mathrm{~min}$ \\
\hline $\begin{array}{l}\text { Asana: Uttanpadasana, } \\
\text { Pabanmuktasana, Sarbangasana, } \\
\text { Halasana, Matyasana, Salvasana, } \\
\text { Dhanurasana (modified), } \\
\text { Bakrasana, Usthrasana, } \\
\text { Suptavajrasana (modified), } \\
\text { Yogmudra Pachimotthanasana, } \\
\text { Tarasana, Trikomasana, and } \\
\text { Katichakrasana }\end{array}$ & $\begin{array}{c}\text { Holding time: } \\
25 \mathrm{sec} \\
15 \times 2 \mathrm{~min}=30 \mathrm{~min}\end{array}$ & 2 times & $10 \mathrm{sec} \times 15 \times 2=5 \mathrm{~min}$ & $35 \mathrm{~min}$ \\
\hline $\begin{array}{l}\text { Pranayana: } \\
\text { Anulome-violme, } \\
\text { Shitali/Shitkari, Bhastrika, and } \\
\text { Ujjai }\end{array}$ & $\begin{array}{c}4 \text { Pranayama } \times 4 \mathrm{~min}= \\
16 \mathrm{~min}\end{array}$ & 5 times & $\begin{array}{c}1 \text { min deep breathing in between } \\
\text { Pranayama } \\
1 \mathrm{~min} \times 4=4 \mathrm{~min}\end{array}$ & $20 \mathrm{~min}$ \\
\hline $\begin{array}{l}\text { Meditation: } \\
\text { A-U-M or complete "AUM" } \\
\text { chanting }\end{array}$ & Practice span: $10 \mathrm{~min}$ & $\begin{array}{l}\text { Depend upon } \\
\text { individual } \\
\text { capacity }\end{array}$ & Complete relaxation during recitation & $10 \mathrm{~min}$ \\
\hline \multicolumn{5}{|c|}{ Total time: 105 minutes } \\
\hline
\end{tabular}


TABLE 8: Detailed yogic practice protocol for 8 th to 12 th weeks (105-minute schedule, $1.45 \mathrm{hrs}$ ) combination-2 (2 days/week, Tuesday and Thursday).

\begin{tabular}{|c|c|c|c|c|}
\hline Name of yogic practices & Execution time & Repetitions & Recovery time & Total time \\
\hline Suryanamaskar & $25 \mathrm{sec} \times 15=6.25 \mathrm{~min}$ & 15 times & $15 \mathrm{sec} \times 15=3.75 \mathrm{~min}$ & $10 \mathrm{~min}$ \\
\hline Kriya: Kapalbhati & 60 strokes @ 2 stroke $/ \mathrm{sec}=2.5 \mathrm{~min}$ & 5 times & $30 \mathrm{sec} \times 5$ times $=2.5 \mathrm{~min}$ & \multirow{2}{*}{$10 \mathrm{~min}$} \\
\hline Uddyan and Agnisara & $30 \mathrm{sec} \times 3 \times 2=3 \mathrm{~min}$ & 3 times & $20 \mathrm{sec} \times 2 \times 3=2 \mathrm{~min}$ & \\
\hline $\begin{array}{l}\text { Asana: Uttanpadasana, } \\
\text { Pabanmuktasana, Sarbangasana, } \\
\text { Halasana, Matyasana, Salvasana, } \\
\text { Dhanurasana (modified), Bakrasana, } \\
\text { Usthrasana, Suptavajrasana } \\
\text { (modified), Yogmudra } \\
\text { Pachimotthanasana, Tarasana, } \\
\text { Trikomasana, and Katichakrasana }\end{array}$ & Holding time: $25 \mathrm{sec}$ & 2 times & $10 \mathrm{sec} \times 15 \times 2=5 \mathrm{~min}$ & $35 \mathrm{~min}$ \\
\hline $\begin{array}{l}\text { Pranayana: } \\
\text { Anulome-violme, Shitali/Shitkari, } \\
\text { Bhastrika, Ujjai, and Bharamari }\end{array}$ & 5 Pranayama $\times 4 \min =20 \mathrm{~min}$ & 5 times & $\begin{array}{l}1 \text { min deep breathing in } \\
\text { between Pranayama } \\
1 \text { min } \times 5=5 \text { min }\end{array}$ & $25 \mathrm{~min}$ \\
\hline $\begin{array}{l}\text { Meditation: } \\
\text { Yog Nidra }\end{array}$ & Practice span: 25 min & - & $\begin{array}{l}\text { Complete relaxation during } \\
\text { the practice }\end{array}$ & $25 \min$ \\
\hline \multicolumn{5}{|c|}{ Total time: 105 minutes } \\
\hline
\end{tabular}

TABLE 9: Detailed yogic practice protocol for 8 th to 12 th weeks (105-minute schedule, $1.45 \mathrm{hrs)} \mathrm{combination-3} \mathrm{(2} \mathrm{days/week,} \mathrm{Wednesday} \mathrm{and}$ Saturday).

\begin{tabular}{|c|c|c|c|c|}
\hline Name of yogic practices & Execution time & Repetitions & Recovery time & Total time \\
\hline Suryanamaskar & $25 \mathrm{sec} \times 15=6.25 \mathrm{~min}$ & 15 Times & $15 \mathrm{sec} \times 15=3.75 \mathrm{~min}$ & $15 \mathrm{~min}$ \\
\hline Kriya: Kapalbhati & 80 strokes@ 2 stroke $/ \mathrm{sec}=4 \mathrm{~min}$ & 6 times & $60 \mathrm{sec} \times 6$ times $=6 \mathrm{~min}$ & $10+5=15 \mathrm{~min}$ \\
\hline Uddyan and Agnisara & $30 \mathrm{sec} \times 3 \times 2=3 \mathrm{~min}$ & 3 times & $20 \mathrm{sec} \times 2 \times 3=2 \mathrm{~min}$ & \\
\hline $\begin{array}{l}\text { Asana: Uttanpadasana, } \\
\text { Pabanmuktasana, Viparitkaranisana, } \\
\text { Halasana, Matyasana, Salvasana, } \\
\text { Dhanurasana (modified), Bakrasana, } \\
\text { Usthrasana, Suptavajrasana } \\
\text { (modified), Yogmudra } \\
\text { Pachimotthanasana, Tarasana, } \\
\text { Trikomasana, and Katichakrasana }\end{array}$ & $15 \times 2.5 \mathrm{~min}=37.5 \mathrm{~min}$ & 3 times & $10 \mathrm{sec} \times 15 \times 3=7.5 \mathrm{~min}$ & $45 \mathrm{~min}$ \\
\hline $\begin{array}{l}\text { Pranayana: } \\
\text { Anulome-violme, Shitali/Shitkari, } \\
\text { Bhastrika, Ujjai, and Bharamari }\end{array}$ & 5 Pranayama $\times 4 \mathrm{~min}=20 \mathrm{~min}$ & 5 times & $\begin{array}{l}1 \text { min deep breathing in } \\
\text { between Pranayama } \\
1 \text { min } \times 5=5 \text { min }\end{array}$ & $25 \mathrm{~min}$ \\
\hline $\begin{array}{l}\text { Meditation: } \\
\text { A-U-M or complete "AUM" chanting }\end{array}$ & Practice span: 5 min & $\begin{array}{l}\text { Depend upon } \\
\text { individual } \\
\text { capacity }\end{array}$ & $\begin{array}{l}\text { Complete relaxation during } \\
\text { recitation }\end{array}$ & $5 \mathrm{~min}$ \\
\hline
\end{tabular}

32.15\% ( $P<0.01$, paired $t$-test, pretest versus midtest) after six and $48.50 \%(P<0.001$, paired $t$-test, pretest versus posttest) after twelve weeks of yogic training as compared with the baseline value, whereas changes were negligible in control group during this twelve weeks (Figures 4 and 5). The ANOVA results are summarized in Table 13.

\section{Discussion}

The main findingof the present experiment is that the combined approach of graded yogic training is positive and associated with increased basal level of GH and DHEAS in the blood. It also appears from the results that combined yogic practices are a productive means for the maintenance of body weight in the middle age. $\mathrm{BMI}$ is a standard (WHO) index for the expression of general health. This numerical value may indicate malnutrition in the lower range and obesity in the higher range. The change of BMI in the experimental group was for the decrease of body weight which supporta the result of previous studies [40-44].

All endocrine glands are subject to the effects of aging [16]. GH output is relatively low before puberty but with 
TABLE 10: Baseline characteristics (independent " $t$ " test).

\begin{tabular}{lccc}
\hline $\begin{array}{l}\text { Sl. } \\
\text { number }\end{array}$ & Variables & $\begin{array}{c}\text { Male (experimental } \\
\text { pretest versus control } \\
\text { pretest) }\end{array}$ & $\begin{array}{c}\text { Female (experimental } \\
\text { pretest versus control } \\
\text { pretest) }\end{array}$ \\
\hline 1. & $\begin{array}{c}\text { Body } \\
\text { weight } \\
\text { Body mass } \\
\text { index }\end{array}$ & $P=0.49$ & $P=0.99$ \\
2. & $P=0.40$ & $P=0.76$ \\
3. & hGH & $P=0.85$ & $P=0.44$ \\
4. & DHEAS & $P=0.71$ & $P=0.72$ \\
\hline
\end{tabular}

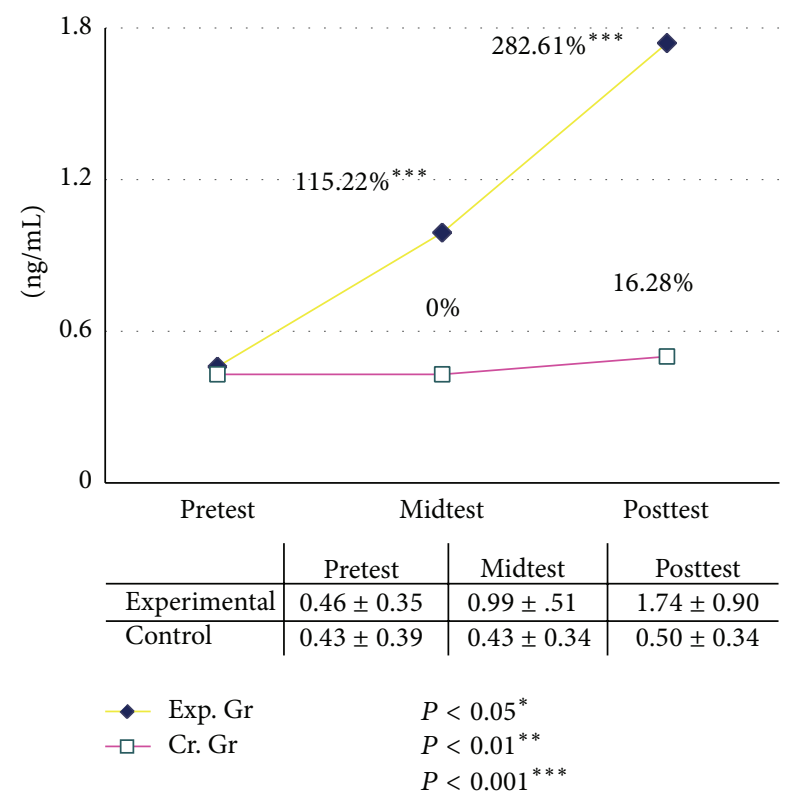

FIGURE 2: Human growth hormone (hGH) male.

sexual maturations and adolescence there is a period of high $\mathrm{GH}$ output and accelerating somatic growth [45]. GH secretion and serum GH concentrations fall, both basally and in response to stimuli. In older subjects the decrease in growth hormone secretion is known to cause a reduction of protein synthesis, a decrease in lean body mass and bone mass, and a decline in immune function [46]. It can be revealed that previous research studies were conducted to observe the effect of yoga on $\mathrm{GH}$ response. Growth hormone concentration was unchanged before, during, and after transcendental meditation (TM) in the long-term transcendental meditation practitioner group, restudied controls and control group [30]. GH concentrations fell slightly in the TM group and in the control group during the postmeditation/relaxation period, the trend being more apparent in meditators [32]. Werner et al. [33] reported that a progressive decrease in $\mathrm{GH}$ level occurred over three years of transcendental meditation programme. MacLean et al. [31] observed the baseline and responses to laboratory stressors for growth hormone either after the 4 months of TM programme or a stress education control programme. Growth hormone increased after 4 months of TM meditation in response to laboratory stress session.

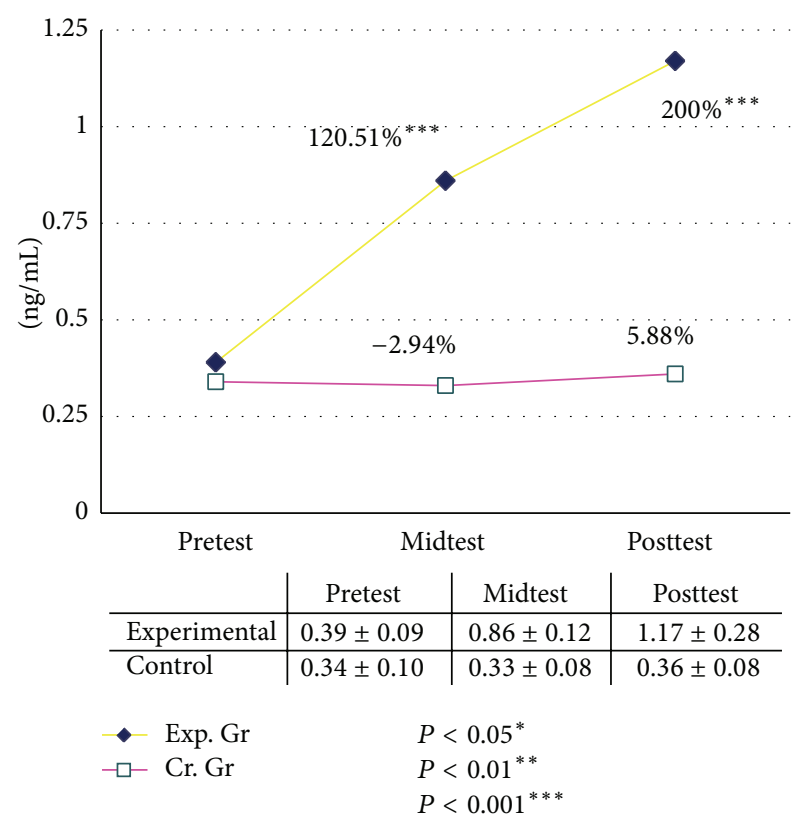

FIgURE 3: Human growth hormone (hGH) female.

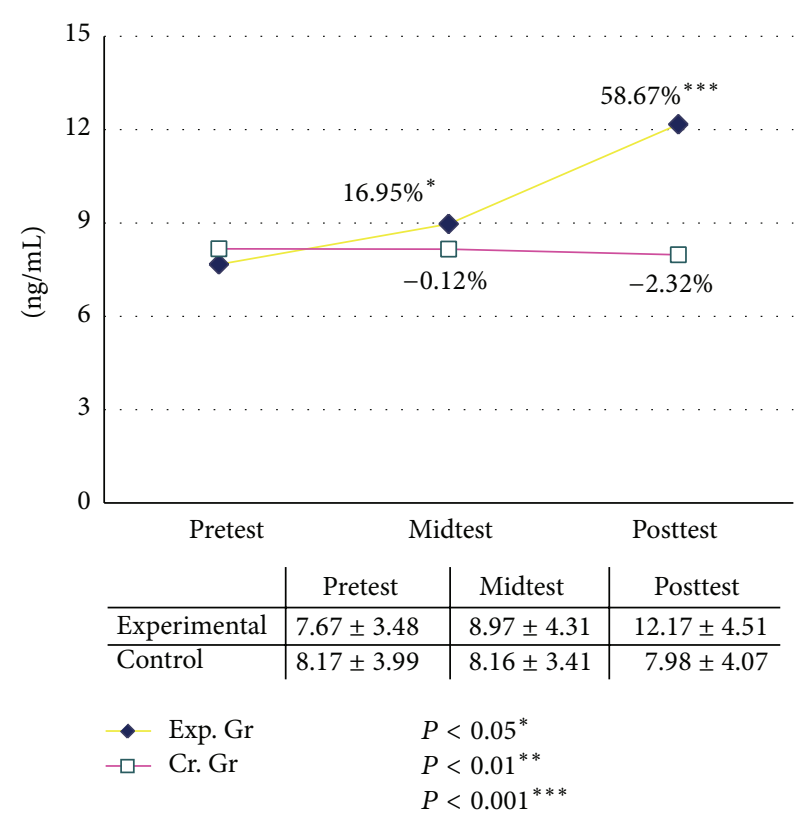

Figure 4: Dehydroepiandrosterone sulfate (DHEAS) male.

Most of the above reports of yoga on growth hormone have dealt with transcendental meditation. Transcendental meditation gives rise to a unique state of deep rest by marked reductions in resting heart rate, respiratory rate, oxygen consumption, and metabolic activity [47-49]; increased cerebral blood flow $[30,49,50]$ may be responsible for the decrease of growth hormone in the human body. These results of TM technique also suggest meditation may produce mental alertness with physiological relaxations.

In contrast to our pilot study, it was observed that six weeks combined yoga intervention produce an insignificant 
TABLE 11: General and endocrine variables of experimental and waitlist control group (Mean \pm SD).

\begin{tabular}{|c|c|c|c|c|c|c|}
\hline \multirow[b]{2}{*}{ Components } & \multicolumn{3}{|c|}{ Experimental group (yoga) } & \multicolumn{3}{|c|}{ Control group (wait list) } \\
\hline & Pretest & $\begin{array}{c}\text { Midtest } \\
\text { (pre. versus } \\
\text { mid.) }\end{array}$ & $\begin{array}{c}\text { Posttest } \\
\text { (pre. versus } \\
\text { post.) }\end{array}$ & Pretest & $\begin{array}{c}\text { Midtest } \\
\text { (pre. versus mid.) }\end{array}$ & $\begin{array}{c}\text { Posttest } \\
\text { (pre. versus post.) }\end{array}$ \\
\hline Body weight $(\mathrm{Kg})[$ male $]$ & $70.36 \pm 14.14$ & $69.93 \pm 13.64$ & $69.2 \pm 13.64^{*}$ & $74.19 \pm 15.81$ & $74.2 \pm 15.75$ & $74.27 \pm 15.70$ \\
\hline Body weight (Kg) [female] & $64.26 \pm 8.87$ & $63.27 \pm 8.68^{* *}$ & $62.4 \pm 8.0^{* * *}$ & $64.21 \pm 8.88$ & $64.07 \pm 8.87$ & $63.05 \pm 8.85$ \\
\hline BMI $\left(\mathrm{Kg} / \mathrm{Mt}^{2}\right)$ [male] & $24.33 \pm 4.33$ & $24.17 \pm 4.22$ & $23.93 \pm 4.22^{*}$ & $25.64 \pm 4.23$ & $25.65 \pm 4.02$ & $25.68 \pm 3.42$ \\
\hline $\mathrm{BMI}\left(\mathrm{Kg} / \mathrm{Mt}^{2}\right)$ [female] & $25.89 \pm 3.47$ & $25.49 \pm 3.66^{* *}$ & $25.13 \pm 3.48^{* * *}$ & $26.4 \pm 3.13$ & $26.34 \pm 3.03$ & $26.39 \pm 2.75$ \\
\hline hGH (ng/mL) [male] & $0.46 \pm 0.35$ & $0.99 \pm 0.51^{* * *}$ & $1.74 \pm 0.09^{* * *}$ & $0.43 \pm 0.39$ & $0.43 \pm 0.34$ & $0.54 \pm 0.03$ \\
\hline $\mathrm{hGH}(\mathrm{ng} / \mathrm{mL})[$ female] & $0.39 \pm 0.09$ & $0.86 \pm 0.12^{* * *}$ & $1.74 \pm 0.28$ & $0.34 \pm 0.10$ & $0.33 \pm 0.08$ & $0.36 \pm 0.08$ \\
\hline DHEAS (ng/mL) [male] & $7.76 \pm 3.48$ & $8.97 \pm 4.31^{*}$ & $12.17 \pm 4.51^{* * *}$ & $8.17 \pm 3.99$ & $8.16 \pm 3.41$ & $7.98 \pm 4.07$ \\
\hline DHEAS (ng/mL) [Ffemale] & $3.67 \pm 1.46$ & $4.85 \pm 2.17^{* *}$ & $5.45 \pm 1.15^{* * *}$ & $3.33 \pm 1.51$ & $3.38 \pm 1.52$ & $3.42 \pm 1.35$ \\
\hline
\end{tabular}

${ }^{*} P<0.05,{ }^{* *} P<0.01$, and ${ }^{* * *} P<0.001$; two tailed, $t$-test for paired data comparing the values at six weeks (midtest) versus baseline (pretest) and twelve weeks (posttest) versus baseline (pretest).

TABLE 12: Growth hormone (analysis of variance).

\begin{tabular}{|c|c|c|c|c|c|c|}
\hline Source & $\begin{array}{c}\text { Type III sum of } \\
\text { squares }\end{array}$ & $\mathrm{df}$ & Mean square & $F$ & $\begin{array}{c}\text { Sig. } \\
(P \text { value })\end{array}$ & Eta squared \\
\hline \multicolumn{7}{|c|}{ Male } \\
\hline $\begin{array}{l}\text { Within subjects factor } \\
\text { (time: pretest, midtest, and } \\
\text { posttest) }\end{array}$ & 6.780 & 1 & 6.780 & 31.425 & 0.000 & 0.529 \\
\hline $\begin{array}{l}\text { Between subjects factor } \\
\text { (groups: experimental and } \\
\text { wait list control) }\end{array}$ & 8.354 & 1 & 8.354 & 16.678 & 0.000 & 0.373 \\
\hline $\begin{array}{l}\text { Interaction } \\
\text { time } * \text { group }\end{array}$ & 5.575 & 1 & 5.575 & 25.840 & 0.000 & 0.480 \\
\hline $\begin{array}{l}\text { Error } \\
\text { (within subjects factor) }\end{array}$ & 6.042 & 28 & 0.216 & & & \\
\hline $\begin{array}{l}\text { Error } \\
\text { (between subjects factor) }\end{array}$ & 14.025 & 28 & 0.501 & & & \\
\hline \multicolumn{7}{|c|}{ Female } \\
\hline $\begin{array}{l}\text { Within subjects factor } \\
\text { (time: pretest, midtest, and } \\
\text { posttest) }\end{array}$ & 4.371 & 1 & 4.371 & 47.499 & 0.000 & 0.856 \\
\hline $\begin{array}{l}\text { Between subjects factor } \\
\text { (groups: experimental and } \\
\text { wait list control) }\end{array}$ & 12.339 & 1 & 12.339 & 1.804 & 0.216 & 0.184 \\
\hline $\begin{array}{l}\text { Interaction } \\
\text { time } * \text { group }\end{array}$ & 3.570 & 1 & 3.570 & 38.795 & 0.000 & 0.829 \\
\hline $\begin{array}{l}\text { Error } \\
\text { (within subjects factor) }\end{array}$ & 0.736 & 13 & 9.203 & & & \\
\hline $\begin{array}{l}\text { Error } \\
\text { (between subjects factor) }\end{array}$ & 54.718 & 13 & 6.840 & & & \\
\hline
\end{tabular}

increase in the basal level of GH [51]. Also in this present study, maintaining all the methodological formalities except randomized control trial, again it was observed that $\mathrm{GH}$ level increased significantly after six and twelve weeks of yogic practices for male and female middle aged group. In the graded yogic training schedule there were suryanamaskara (sun salutation), shithilikarana (loosening) practices, and asanas (physical postures) which were reported as moderate aerobic type of exercises [52-56] and may positively influence the basal level of GH in the plasma blood. There are many exercise and sports scientists who have reported the same that regular moderate exercise habit may improve/increase basal levels of $\mathrm{GH}$ in the human subjects $[13,15,57]$ which positively support our findings.

On the other hand different cross-sectional studies also provided some important mechanisms. GH and Insulin like growth factor-I (IGF-I) influence the function of the hippocampus, a brain structure important for the maintenance 
TABLE 13: Dehydroepiandrosterone sulfate hormone (analysis of variance).

\begin{tabular}{|c|c|c|c|c|c|c|}
\hline Source & $\begin{array}{c}\text { Type III sum } \\
\text { of squares }\end{array}$ & df & Mean square & $F$ & $\begin{array}{c}\text { Sig. } \\
(P \text { value })\end{array}$ & Eta squared \\
\hline \multicolumn{7}{|c|}{ Male } \\
\hline $\begin{array}{l}\text { Within subjects factor } \\
\text { (time: pretest, midtest, and } \\
\text { posttest) }\end{array}$ & 69.768 & 1 & 69.768 & 21.748 & 0.000 & 0.437 \\
\hline $\begin{array}{l}\text { Between subjects factor } \\
\text { (groups: experimental and } \\
\text { wait list control) }\end{array}$ & 50.580 & 1 & 50.580 & 1.208 & 0.281 & 0.041 \\
\hline $\begin{array}{l}\text { Interaction } \\
\text { time } * \text { group }\end{array}$ & 82.415 & 1 & 82.415 & 25.690 & 0.000 & 0.478 \\
\hline $\begin{array}{l}\text { Error } \\
\text { (within subjects factor) }\end{array}$ & 89.825 & 28 & 3.202 & & & \\
\hline $\begin{array}{l}\text { Error } \\
\text { (between subjects factor) }\end{array}$ & 1171.933 & 28 & 41.855 & & & \\
\hline \multicolumn{7}{|c|}{ Female } \\
\hline $\begin{array}{l}\text { Within subjects factor } \\
\text { (time: pretest, midtest, and } \\
\text { posttest) }\end{array}$ & 0.792 & 1 & 0.792 & 23.303 & 0.001 & 0.744 \\
\hline $\begin{array}{l}\text { Between subjects factor } \\
\text { (groups: experimental and } \\
\text { wait list control }\end{array}$ & 1.587 & 1 & 1.587 & 70.123 & 0.000 & 0.898 \\
\hline $\begin{array}{l}\text { Interaction } \\
\text { time } * \text { group }\end{array}$ & 0.707 & 1 & 0.707 & 20.798 & 0.002 & 0.722 \\
\hline $\begin{array}{l}\text { Error } \\
\text { (within subjects factor) }\end{array}$ & 0.272 & 13 & 3.399 & & & \\
\hline $\begin{array}{l}\text { Error } \\
\text { (between subjects factor) }\end{array}$ & 0.181 & 13 & 2.263 & & & \\
\hline
\end{tabular}

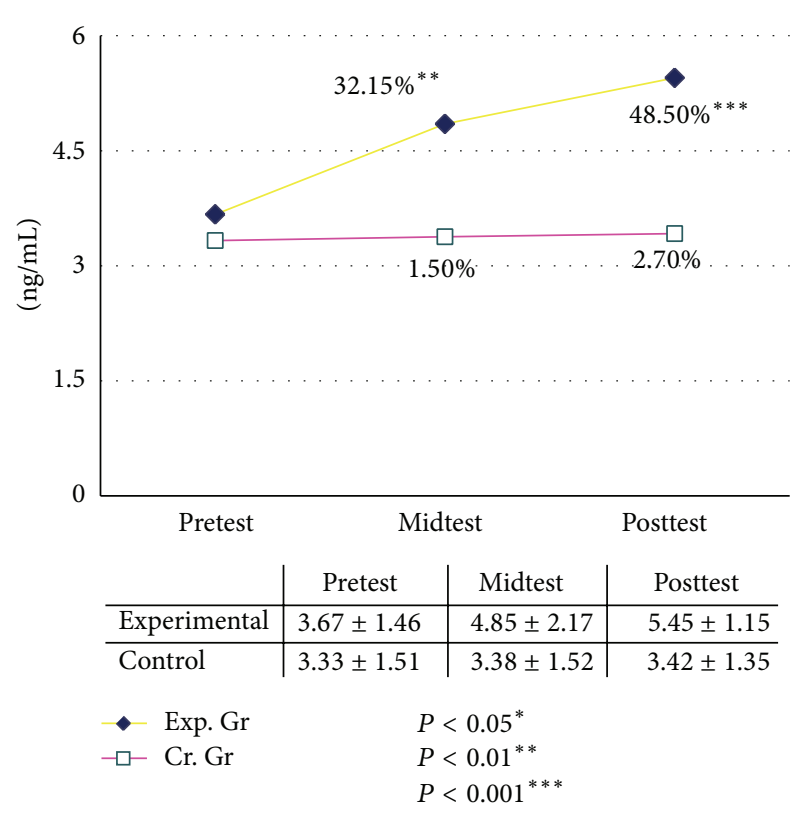

FIGURE 5: Dehydroepiandrosterone sulfate (DHEAS) female.

of cognitive functions such as learning, perception, and memory. Several studies mention that GH or IGF-I deficiency is associated with the deterioration of cognitive functions
[58-60]. Cognitive abilities have been improved after regular practice of yoga [61-67]; this central adaptation mechanism may influence the improvement of $\mathrm{GH}$ level. $\mathrm{VO}_{2}$ as a marker of fitness is an independent predictor of peak $\mathrm{GH}$ secretion. Hatha yoga practices increased the physical fitness [6871 ] and aerobic capacity after immediate practice of asana $[56,72,73]$ that may influence the increase of $\mathrm{GH}$ levels in the blood. Insulin like growth factor-I (IGF-I) and GH production are positively correlated; increase of IGF-I after moderate exercise may be another possible mechanism for the improvement of GH secretion [74]. Deep sleep increase GH secretion [75], meditation, is an alert full deep resting state associated with high alfa waves, very similar to the stage of deep sleep that may increase GH secretion. There was an established relationship between decrease cortisol level and increased GH level $[14,76]$. Cortisol level has been decreased significantly after practice of yoga may be another possible cause of increasing GH. The levels of GH have positively correlated with the secretion of DHEA/DHEAS [4]; in the present study the DHEAS secretion increased significantly after yogic training may have a positive impact on increased basal level of GH.

Dehydroepiandrosterone sulfate (DHEAS) is secreted from the deep layer of adrenal cortex and is called zona reticularis [77]. The blood level of DHEAS peaks at approximately 20-25 years of age and declines rapidly and markedly after the age of 30 years [78]. 
Dehydroepiandrosterone (DHEA) increased in six and decreased in two healthy subjects after immediate practice of cobra posture (bhujangasana) in a group of 22-25 yrs aged healthy subjects [79]. Glaser et al. [35] measured DHEAS level in transcendental meditation practitioner of different age group. They compared all the groups with age matched men and women and found 6\% elevation in the 42-44-yearage group; $13 \%$ in the $45-49$-year group; $54 \%$ in the $50-$ 55 -year group, whereas in the female group elevation was reported as $28 \%$ in the $35-39$-year group; $28 \%$ in the $40-44$ year group; $34 \%$ in the $45-49$-year group; $54 \%$ in the $50-$ 54 -year group; and 29\% in the 55-59-year group. Vera et al. [36] reported that DHEAS level in the yoga group was $137.15 \pm 53.08 \mathrm{ug} / \mathrm{dL}$ and, in the control group, it was $118.18 \pm$ $58.86 \mathrm{ug} / \mathrm{dL}$. The reports of the above studies were a very close proximity with this present research. The combined (Kriya, Suryanamaskara, Asana, Pranayama, and Meditation) practice of yoga produce a significant improvement of serum DHEAS level after six and twelve weeks of graded yogic training.

Convenient sampling (not randomized control trial) and the fact that no residential camp was conducted can be considered to a certain extent as limitations of the study. Within the limitations of the study, the researcher would like to present the prospective mechanisms of yoga for increasing the following basal level of $\mathrm{GH}$ and DHEAS after regular graded combined yogic practices for a period of twelve weeks.

(i) Mind and body are not separate entity in yoga. The practice of Kriya, Suryanamaskara and Asana (physical level), Pranayama (psychophysiological level), and Meditation (psychoneurological level) integrate and harmonise mind and body to provide an ideal neuroglandular adjustment within the individual and may positively stimulate the $\mathrm{GH}$ and DHEAS secretion pattern in the middle aged persons.

(ii) Kriyas or cleaning processes (Kapalbhati, Agnisara, Uddiyan Jalaneti, Sutraneti, and Vamandhauti) bring in control over the autonomic nervous system function [17]. This may send positive feedback to the hypothalamus-pituitary axis which could influence the basal GH production in the blood. Kapalbhati, Agnisara, and Uddiyan give vigorous abdominal movements and an automatic abdominal massage may preserve the health of adrenal gland and thus improve DHEAS concentration in the blood. Kriyas bring about a widened range of adaptability of the tissues forming the various systems and organs as also raise the threshold of their reactivity. Voluntary control is established on different reflexes through the cleaning processes. Autonomic and proprioceptive neuromuscular reactions seem to have an important bearing in bringing about these results $[80,81]$.

(iii) Suryanamaskara or salutation to the sun is an important yogic practice which has been handed down from the sages of Vedic time. Suryanamaskara is almost a complete sadhana in itself [82]. It is a series of dynamic movements (12 counts) of forward and backward spinal bends and stretches with body and breathing awareness improve major muscle group in the body, strengthen joint structure and range of motion, digestion, circulation, aerobic capacity, body's circadian rhythms, nourishment, and stimulation of the nerves [83-87]. With this it is also equally activate and stimulates all the glands in the body including pituitary and adrenal to get a positive neuroendocrine feedback for maintaining a healthy secretion of GH and DHEAS.

(iv) Cultural asanas (static physical posture with internal body awareness) provides a constant supply of proper nutrition to the tissues and the internal secretion of the endocrine glands [88]. The hypothalamopituitary axis is best taken care of by antigravitational postures, for example, Sarvangasana, Viparitkarana Asana, and Sirshasana. So far as the adrenals are concerned, Pavanmuktasana, Halasana, Paschimottanasana, Bhujanga, Salvasana, Dhanurasana, Usthrasana, Bakrasana, and Yogmudra Asana are capable of preserving their health which may positively influence the basal plasma level of DHEAS in the body. Erect position of the spine in meditative asanas, for example, Padmasana and Vajrasana, eliminate the possibility of the compression of the abdominal viscera and also free the mind from the burden of the body, richer blood supply to the pelvic region, and minimum production of carbon dioxide in the body due to laser muscular involvement produce a parasympathetic dominance which may indirectly influence the GH and DHEAS basal level in the body.

(v) In the machinery of human body a liberal supply of oxygen to the circulating blood is of supreme importance for the health of an individual. This supply is effectively improved by means of pranayama (scientific breathing practices). This richer and more liberal blood supply brought to the endocrine glands makes them healthier [89]. Regular practice of different forms of Pranyama (Anulome-vilome, Surya Vedhana, Chandra Vedhana, Ujjai, Bhastrika, Shitali, and Sitkari) increases psychophysiological relaxation by quieting and calming the mind, decreases sympathetic tone, and enhances parasympathetic activation [90-92] which may positively influence the basal level of GH and DHEAS concentration in the blood.

(vi) Meditation is believed to gradually diminish sympathetic dominance, resulting in a better balance between the sympathetic and the parasympathetic activity [93]. It also brings about a hypometabolic state [94]. By modifying the state of tension and anxiety, mediation reduces stress induced sympathetic over reactivity $[93,95,96]$. Thus a decrease in sympathetic response and ability to overcome stress can be a possible reason for the improvement in $\mathrm{GH}$ and DHEAS in the plasma blood. 


\section{Conclusion}

Finally from the findings of the present study and from the above elaborate discussion, it can be concluded that combined approach of yoga (Kriya, Suryanamaskara, Asana, Pranayama, and Meditation) significantly increases the basal level of GH and DHEAS in the blood, thus contributing in promoting healthy aging. The results of the present study also support the claim made by the seers and sages of India in the ancient yogic texts.

\section{Conflict of Interests}

The authors declare that there is no conflict of interests regarding the publication of this paper.

\section{Acknowledgments}

The authors are grateful to Central Council for Research in Yoga and Naturopathy (CCRYN); Department of AYUSH, Ministry of Health and Family Welfare, Government of India for their financial support. They acknowledge "Joynto Smriti Sangha" (community health club) for their support and active help to organized the "Yoga and Health Awareness Camp" in the community. They are also thankful to the administration of Visva-Bharati University and specially the P.M. Hospital for laboratory setup and technical help for smooth conduction of the study. Finally they really appreciate the support and cooperation of the sampled subjects of this study.

\section{References}

[1] F. Lanfranco, L. Gianotti, R. Giordano, M. Pellegrino, M. Maccario, and E. Arvat, "Ageing, growth hormone and physical performance," Journal of Endocrinological Investigation, vol. 26, no. 9, pp. 861-872, 2003.

[2] K. Stokes, "Growth hormone responses to sub-maximal and sprint exercise," Growth Hormone and IGF Research, vol. 13, no. 5, pp. 225-238, 2003.

[3] K. A. Stokes, M. E. Nevill, P. W. Cherry, H. K. A. Lakomy, and G. M. Hall, "Effect of 6 weeks of sprint training on growth hormone responses to sprinting," European Journal of Applied Physiology, vol. 92, no. 1-2, pp. 26-32, 2004.

[4] T. Kostka, "Aging and so called "youth hormones". Potential influence of exercise training," Przeglad Lekarski, vol. 58, no. 1, pp. 25-27, 2001.

[5] S. Perrini, L. Laviola, A. Natalicchio, and F. Giorgino, "Associated hormonal declines in aging: DHEAS," Journal of Endocrinological Investigation, vol. 28, no. 3, supplement, pp. 85-93, 2005.

[6] T. V. Dennis and O. H. John, "DHEA enhances effects of weight training on muscle mass and strength in elderly women and men," American Journal of Physiology-Endocrinology and Metabolism, vol. 291, no. 5, pp. E1003-E1008, 2006.

[7] R. S. Mazzeo, "Aging, immune function, and exercise: hormonal regulation," International Journal of Sports Medicine, vol. 21, supplement 1, pp. s10-s13, 2000.
[8] W. Leowattana, "DHEA(S): the fountain of youth," Journal of the Medical Association of Thailand, vol. 84, supplement 2, pp. S605-S612, 2001.

[9] M. Hermann and P. Berger, "Hormonal changes in aging men: a therapeutic indication?" Experimental Gerontology, vol. 36, no. 7, pp. 1075-1082, 2001.

[10] B. Corrigan, "DHEA and sport," Clinical Journal of Sport Medicine, vol. 12, no. 4, pp. 236-241, 2002.

[11] D. Heutling and H. Lehnert, "Hormone therapy and anti-aging: is there an indication?" Internist, vol. 49, no. 5, pp. 570-580, 2008.

[12] M. R. Ambrosio, A. Valentini, G. Trasforini et al., "Function of the GH/IGF-1 axis in healthy middle-aged male runners," Neuroendocrinology, vol. 63, no. 6, pp. 498-503, 1996.

[13] S. J. Hurel, N. Koppiker, J. Newkirk et al., "Relationship of physical exercise and ageing to growth hormone production," Clinical Endocrinology, vol. 51, no. 6, pp. 687-691, 1999.

[14] O. Tissandier, G. Peres, J. Fiet, and F. Piette, “Testosterone, dehydroepiandrosterone, insulin-like growth factor 1, and insulin in sedentary and physically trained aged men," European Journal of Applied Physiology, vol. 85, no. 1-2, pp. 177-184, 2001.

[15] G. Ravaglia, P. Forti, F. Maioli et al., "Regular moderate intensity physical activity and blood concentrations of endogenous anabolic hormones and thyroid hormones in aging men," Mechanisms of Ageing and Development, vol. 122, no. 2, pp. 191203, 2001.

[16] H. S. Chahal and W. M. Drake, "The endocrine system and ageing," Journal of Pathology, vol. 211, no. 2, pp. 173-180, 2007.

[17] S. Muktibodhananda, Hatha Yoga Prdipika, Yoga Publication Trust, Munger, Bihar, India, 2000.

[18] S. Digambaraji and M. L. Gharote, Gheranda Samhita, Kaivalyadhama, S.M.Y.M. Samiti, Lonavla, India, 2nd edition, 1997.

[19] S. Digambaraji and R. S. P. Kokaje, Hatha Prodipika of Svatmarama, Kaivalyadhama, S.M.Y.M. Samiti, Lonavla, India, 2nd edition, 1998.

[20] S. Mumukshananda, Meditation and Its Preparation, The Ramakrishna Mission Institute of Culture, Kolkata, India, 2000.

[21] S. N. Saraswati, Prana Pranayama Prana Vidya, Yoga Publication Trust, Munger, India, 2002.

[22] S. S. Saraswati, Asana Pranayama Mudra Bandha, Yoga Publication Trust, Munger, India, 2002.

[23] S. Maheshananda, B. R. Sharma, G. S. Sahay, and R. K. Bodhe, Vasistha Samhita, Kaivalyadhama S.M.Y.M. Samiti, Lonavla, India, 2005.

[24] S. Maheshananda, B. R. Sharma, G. S. Sahay, R. K. Bodhe, B. K. Jha, and C. L. Bhardwaj, Siva Samhita: A Critical Edition-English Version, Kalyadhama S.M.Y.M. Samiti's Publication, 2009.

[25] M. L. Gharote, Applied Yoga, Kaivalyadhama S.M.Y.M. Samiti, Lonavla, India, 2004.

[26] M. L. Gharote, Yoga Applied to Physical Education, Kaivalyadhama Ashram, Lonavla, India, 2005.

[27] R. Nagarathna and H. R. Nagendra, Integrated Approach of Yoga Therapy for Positive Health, Swami Vivekananda Yoga Prakashana, Bangalore, India, 2006.

[28] K. Kumar, Super Science of Yoga, Standard Publishers, New Delhi, India, 2008.

[29] M. M. Gharote, P. Devnath, and B. K. Jha, Critical Edition of Selected Yogopanisads, Lonavla Yoga Institute, Pune, India, 2009. 
[30] R. Jevning, A. F. Wilson, and E. F. Vanderlaan, "Plasma prolactin and growth hormone during meditation," Psychosomatic Medicine, vol. 40, no. 4, pp. 329-333, 1978.

[31] C. R. K. MacLean, K. G. Walton, S. R. Wenneberg et al., "Effects of the transcendental meditation program on adaptive mechanisms: changes in hormone levels and responses to stress after 4 months of practice," Psychoneuroendocrinology, vol. 22, no. 4, pp. 277-295, 1997.

[32] R. Cooper, B. I. Joffe, and J. M. Lamprey, "Hormonal and biochemical responses to transcendental meditation," Postgraduate Medical Journal, vol. 61, no. 714, pp. 301-304, 1985.

[33] O. R. Werner, R. K. Wallace, and B. Charles, "Long-term endocrinologic changes in subjects practicing the Transcendental Meditation and TM-Sidhi program," Psychosomatic Medicine, vol. 48 , no. $1-2$, pp. $59-66,1986$.

[34] E. J. Schell, B. Allolio, and O. W. Schonecke, "Physiological and psychological effects of Hatha-yoga exercise in health women," International Journal of Psychosomatics, vol. 41, no. 1-4, pp. 4652, 1994.

[35] J. L. Glaser, J. L. Brind, J. H. Vogelman et al., "Elevated serum dehydroepiandrosterone sulfate levels in practitioners of the Transcendental Meditation (TM) and TM-Sidhi programs," Journal of Behavioral Medicine, vol. 15, no. 4, pp. 327-341, 1992.

[36] F. M. Vera, J. M. Manzaneque, E. F. Maldonado et al., "Subjective Sleep Quality and hormonal modulation in long-term yoga practitioners," Biological Psychology, vol. 81, no. 3, pp. 164-168, 2009.

[37] H. Singh, Science of Sports Training, D.V.S. Publication, New Delhi, India, 1st edition, 1997.

[38] J. H. Zar, Biostatistical Analysis. Prentice, Prentice-Hall, New Jersey, NJ, USA, 1999.

[39] J. L. Kepner and D. H. Robinson, "Non- Parametric methods for detecting treatment effects in repeated measures designs," Journal of American Statistical Association, vol. 83, pp. 456-461, 1988.

[40] R. Murugesan, N. Govindarajulu, and T. K. Bera, "Effect of selected yogic practices on the management of hypertension," Indian Journal of Physiology and Pharmacology, vol. 44, no. 2, pp. 207-210, 2000.

[41] S. C. Manchanda, R. Narang, K. S. Reddy et al., "Retardation of coronary atherosclerosis with yoga litestyle intervention," Journal of Association of Physicians of India, vol. 48, no. 7, pp. 687-694, 2000.

[42] J. Yogendra, H. J. Yogendra, S. Ambardekar et al., "Beneficial effects of Yoga lifestyle on reversibility of ischaemic heart disease: caring heart project of international board of Yoga," Journal of Association of Physicians of India, vol. 52, pp. 283-289, 2004.

[43] R. McCaffrey, P. Ruknui, U. Hatthakit, and P. Kasetsomboon, "The effects of yoga on hypertensive persons in Thailand," Holistic Nursing Practice, vol. 19, no. 4, pp. 173-180, 2005.

[44] S. Telles, V. K. Naveen, A. Balkrishna, and S. Kumar, "Short term health impact of a yoga and diet change program on obesity," Medical Science Monitor, vol. 16, no. 1, pp. CR35-CR40, 2010.

[45] C. G. D. Brook and P. C. Hindmarsh, "The somatotropic axis in puberty," Endocrinology and Metabolism Clinics of North America, vol. 21, no. 4, pp. 767-782, 1992.

[46] E. Corpas, S. M. Harman, and M. R. Blackman, "Human growth hormone and human aging," Endocrine Reviews, vol. 14, no. 1, pp. 20-39, 1993.
[47] R. K. Wallace, "Physiological effects of transcendental meditation," Science, vol. 167, no. 3926, pp. 1751-1754, 1970.

[48] R. K. Wallace, H. Benson, and A. F. Wilson, "A wakeful hypometabolic physiologic state," The American Journal of Physiology, vol. 221, no. 3, pp. 795-799, 1971.

[49] R. Jevning, A. F. Wilson, J. P. O’Halloran, and R. N. Walsh, "Forearm blood flow and metabolism during stylized and unstylized states of decreased activation," The American Journal of Physiology, vol. 245, no. 1, pp. R110-R116, 1983.

[50] R. Jevning, W. R. Smith, and A. F. Wilson, "Alteration of blood flow during transcendental meditation," American Journal of Physiology, vol. 24, article 139a, 1976.

[51] S. Chatterjee and S. Mondal, "Effect of yogic exercises on human growth hormone in a middle aged group: a Pilot Study," Yoga Mimamsa, vol. 42, no. 1, pp. 40-47, 2010.

[52] L. Rai and K. Ram, "Energy expenditure and ventilatory responses during Virasana-a yogic standing posture," Indian Journal of Physiology and Pharmacology, vol. 37, no. 1, pp. 4550, 1993.

[53] L. Rai, K. Ram, U. Kant, S. K. Madan, and S. K. Sharma, "Energy expenditure and ventilatory responses during Siddhasanaa yogic seated posture," Indian Journal of Physiology and Pharmacology, vol. 38, no. 1, pp. 29-33, 1994.

[54] M. Hagins, W. Moore, and A. Rundle, "Does practicing hatha yoga satisfy recommendations for intensity of physical activity which improves and maintains health and cardiovascular fitness?" BMC Complementary and Alternative Medicine, vol. 7, article 40, 2007.

[55] B. Sinha, U. S. Ray, A. Pathak, and W. Selvamurthy, "Energy cost and cardiorespiratory changes during the practice of Surya Namaskar," Indian Journal of Physiology and Pharmacology, vol. 48, no. 2, pp. 184-190, 2004.

[56] U. S. Ray, A. Pathak, and O. S. Tomer, "Hatha yoga practices: energy expenditure," Evidence-Based Complementary and Alternative Medicine, vol. 2011, Article ID 241294, 12 pages, 2011.

[57] Z. Ari, N. Kutlu, B. S. Uyanik, F. Taneli, G. Buyukyazi, and T. Tavli, "Serum testosterone, growth hormone, and insulinlike growth factor-1 levels, mental reaction time, and maximal aerobic exercise in sedentary and long-term physically trained elderly males," International Journal of Neuroscience, vol. 114, no. 5, pp. 623-637, 2004.

[58] A. Rollero, G. Murialdo, S. Fonzi et al., "Relationship between cognitive function, growth hormone and insulin-like growth factor I plasma levels in aged subjects," Neuropsychobiology, vol. 38, no. 2, pp. 73-79, 1998.

[59] A. Alman, W. R. devries, J. B. Deijen, E. A. van der veen, E. H. de Haan, and H. P. Koppeschaar, "Growth hormone, insulinlike growth factor I and cognitive function in adults," Growth Hormone and IGF Research, vol. 10, pp. S69-S73, 2000.

[60] P. S. van Dam, A. Aleman, W. R. de Vries et al., "Growth hormone, insulin-like growth factor I and cognitive function in adults," Growth Hormone and IGF Research, vol.10, pp. S69-S73, 2000.

[61] S. Telles, R. Nagarathna, and H. R. Nagendra, "Autonomic changes during "OM" mediation," Indian Journal of Physiology and Pharmacology, vol. 39, no. 4, pp. 418-420, 1995.

[62] N. K. Manjunath and S. Telles, "Improvement in visual perceptual sensitivity in children following yoga training," Journal of India Psychology, vol. 17, no. 2, 1999.

[63] N. K. Manjunath and S. Telles, "Spatial and verbal memory test scores following yoga and fine arts camps for school children," 
Indian Journal of Physiology and Pharmacology, vol. 48, no. 3, pp. 353-356, 2004.

[64] K. V. Naveen, H. R. Nagendra, R. Nagarathna, and S. Telles, "Yoga breathing through a particular nostril increases spatial memory scores without lateralized effects," Psychological Reports, vol. 81, no. 2, pp. 555-561, 1997.

[65] P. Raghuraj and S. Telles, "A randomized trial comparing the effects of yoga and physical activity programs on depth perception in shool children," Journal of Indian Psychology, vol. 21, no. 2, 2003.

[66] V. K. Sharma, S. Das, S. Mondal, U. Goswami, and A. Gandhi, "Effect of Sahaj Yoga on neuro-cognitive functions in patients suffering from major depression," Indian Journal of Physiology and Pharmacology, vol. 50, no. 4, pp. 375-383, 2006.

[67] R. Chattha, R. Nagarathna, V. Padmalatha, and H. R. Nagendra, "Effect of yoga on cognitive functions in climacteric syndrome: a randomised control study," An International Journal of Obstetrics and Gynaecology, vol. 115, no. 8, pp. 991-1000, 2008.

[68] M. D. Tran, R. G. Holly, J. Lashbrook, and E. A. Amsterdam, "Effects of hatha yoga practice on the health-related aspects of physical fitness," Preventive Cardiology, vol. 4, no. 4, pp. 165-170, 2001.

[69] C. C. Clay, L. K. Lloyd, J. L. Walker, K. R. Sharp, and R. B. Pankey, "The metabolic cost of hatha yoga," Journal of Strength and Conditioning Research, vol. 19, no. 3, pp. 604-610, 2005.

[70] S. Telles, M. Dash, and K. V. Naveen, "Effect of yoga on musculoskeletal discomfort and motor functions in professional computer users," Work, vol. 33, no. 3, pp. 297-306, 2009.

[71] T.-L. Chen, H.-C. Mao, C.-H. Lai, C.-Y. Li, and C.-H. Kuo, “The effect of yoga exercise intervention on health related physical fitness in school-age asthmatic children," Hu Li Za Zhi, vol. 56, no. 2, pp. 42-52, 2009.

[72] P. Sarang and S. Telles, "Effects of two yoga based relaxation techniques on Heart Rate Variability (HRV)," International Journal of Stress Management, vol. 13, no. 4, pp. 460-475, 2006.

[73] P. M. Bhutkar, M. V. Bhutkar, G. B. Taware, V. Doijad, and B. R. Doddamani, "Effect of suryanamaskar practice on cardiorespiratory fitness parameters: a pilot study," Al Ameen Journal of Medical Science, vol. 1, no. 2, pp. 126-129, 2008.

[74] D. E. Flanagan, M. C. Taylor, H. V. Parfitt, R. Mardell, P. J. Wood, and B. A. Leatherdale, "Urinary growth hormone following exercise to assess growth hormone production in adults," Clinical Endocrinology, vol. 46, no. 4, pp. 425-429, 1997.

[75] M. V. Vitiello, R. S. Schwartz, D. R. Buchner, K. E. Moe, G. Mazzoni, and G. R. Merriam, "Treating age-related changes in somatotrophic hormones, sleep, and cognition," Dialogues in Clinical Neuroscience, vol. 3, pp. 229-236, 2001.

[76] T. Kostka, M. C. Patricot, B. Mathian, J.-R. Lacour, and M. Bonnefoy, "Anabolic and catabolic hormonal responses to experimental two-set low-volume resistance exercise in sedentary and active elderly people," Aging-Clinical and Experimental Research, vol. 15, no. 2, pp. 123-130, 2003.

[77] S. S. Yen and G. A. Laughlin, "Aging and the adrenal cortex," Experimental Gerontology, vol. 33, no. 7-8, pp. 281-287, 1998.

[78] C. R. Parker Jr., R. L. Mixon, R. M. Brissie, and W. E. Grizzle, "Aging alters zonation in the adrenal cortex of men," The Journal of Clinical Endocrinology and Metabolism, vol. 82, no. 11, pp. 3898-3901, 1997.

[79] R. S. Minvaleev, A. D. Nozdrachev, V. V. Kir'ianova, and A. I. Ivanov, "Postural effects on the hormone level in healthy subjects. Communication I. The cobra posture and steroid hormones," Fiziologiia Cheloveka, vol. 30, no. 4, pp. 88-92, 2004.
[80] M. L. Gharote, Yoga Techniques, The Lonavla Yoga Institute, Lonavla, India, 2nd edition, 2006.

[81] P. Novak and C. Dostalek, "Effect of Madhya nauli on cortical auditory evoked potentials (A topographic study)," Yoga Mimamsa, vol. 28, no. 4, pp. 22-31, 1990.

[82] S. S. Saraswati, Surya Namaskara, Yoga Publications Trust, Munger India, 2007.

[83] R. Choudhary and K. Stec, "Effects of dynamic suryanamaskar on vital capacity of physical education students," Indian Journal of Physical Education, Sports Medicine and Exercise Science, vol. 8, no. 2, pp. 11-12, 2008.

[84] R. Choudhary and K. Stec, "The effects of dynamic on flexibility on university students," Journal of Advances in Developmental Research, vol. 1, no. 1, pp. 45-48, 2010.

[85] R. Choudhary, K. Stec, and L. Kulmatycki, "The effects of dynamic suryanamaskar on positive breath holding capacity of physical education students," Indian Journal of Movement Education and Exercises Sciences (IJMEES), vol. 1, no. 1, 2011.

[86] M. S. Chaya, A. V. Kurpad, H. R. Nagendra, and R. Nagarathna, "The effect of long term combined yoga practice on the basal metabolic rate of healthy adults," BMC Complementary and Alternative Medicine, vol. 6, article 28, 2006.

[87] A. B. Bhavanani, K. Udupa, Madanmohan, and P. N. Ravindra, "A comparative study of slow and fast suryanamaskar on physiological function," International Journal of Yoga, vol. 4, no. 2, pp. 71-76, 2011.

[88] S. Kuvalayananda, Scientific Survey of the Yogic Poses, Kaivalyadhama S.M.Y.M. Samiti, Kaivalyadhama, Lonavala, India, 2nd edition, 2006.

[89] S. Kuvalayananda, Pranayama, Kaivalyadhama, Lonavla, India, 10th edition, 2005.

[90] R. P. Vempati and S. Telles, "Yoga-based guided relaxation reduces sympathetic activity judged from baseline levels," Psychological Reports, vol. 90, no. 2, pp. 487-494, 2002.

[91] S. Telles, R. Nagarathna, H. R. Nagendra, and T. Desiraju, "Physiological changes in sports teachers following 3 months of training in Yoga," Indian Journal of Medical Sciences, vol. 47, no. 10, pp. 235-238, 1993.

[92] S. Telles and T. Desiraju, "Oxygen consumption during pranayamic type of very slow-rate breathing," The Indian Journal of Medical Research, vol. 94, pp. 357-363, 1991.

[93] B. K. Anand, "Yoga and medical sciences," Indian Journal of Physiology and Pharmacology, vol. 35, no. 2, pp. 84-87, 1991.

[94] B. K. Anand, "Neurophysiological concepts of consciousness," Neurology India, vol. 13, no. 4, pp. 173-175, 1965.

[95] B. K. Ananda, "Physiological concepts of consciousness," Indian Journal of Physiology and Pharmacology, vol. 4, pp. 155-167, 1960.

[96] V. D. Deshmukh, “Neuroscience of meditation," The Scientific World Journal, vol. 6, pp. 2239-2253, 2006. 


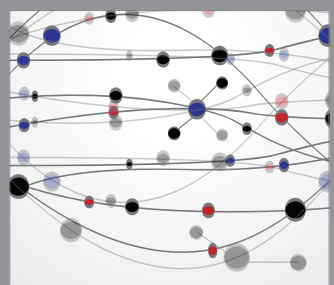

The Scientific World Journal
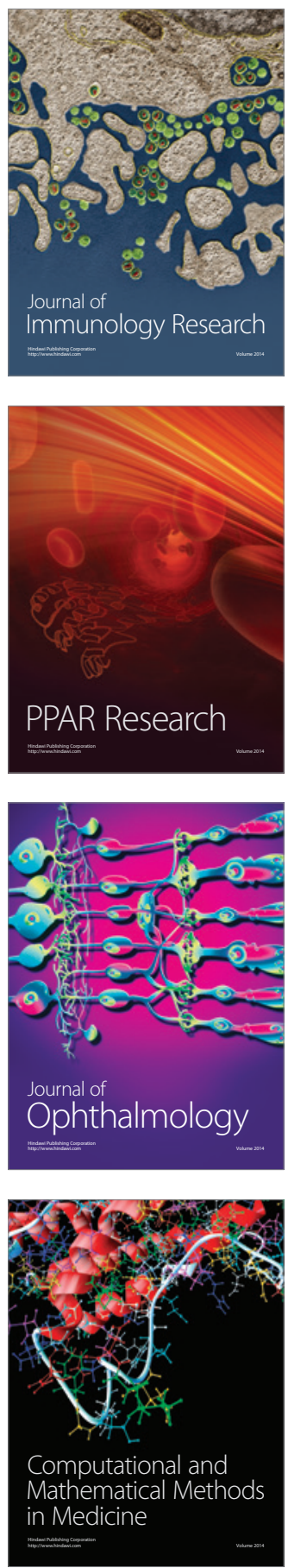

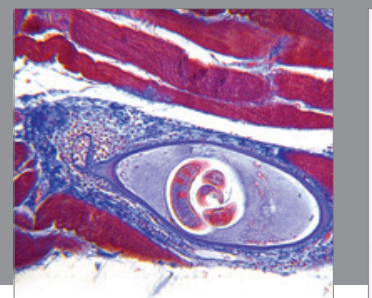

Gastroenterology

Research and Practice
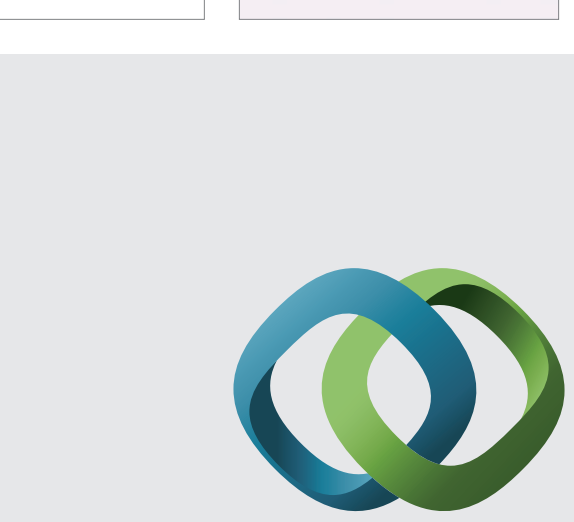

\section{Hindawi}

Submit your manuscripts at

http://www.hindawi.com
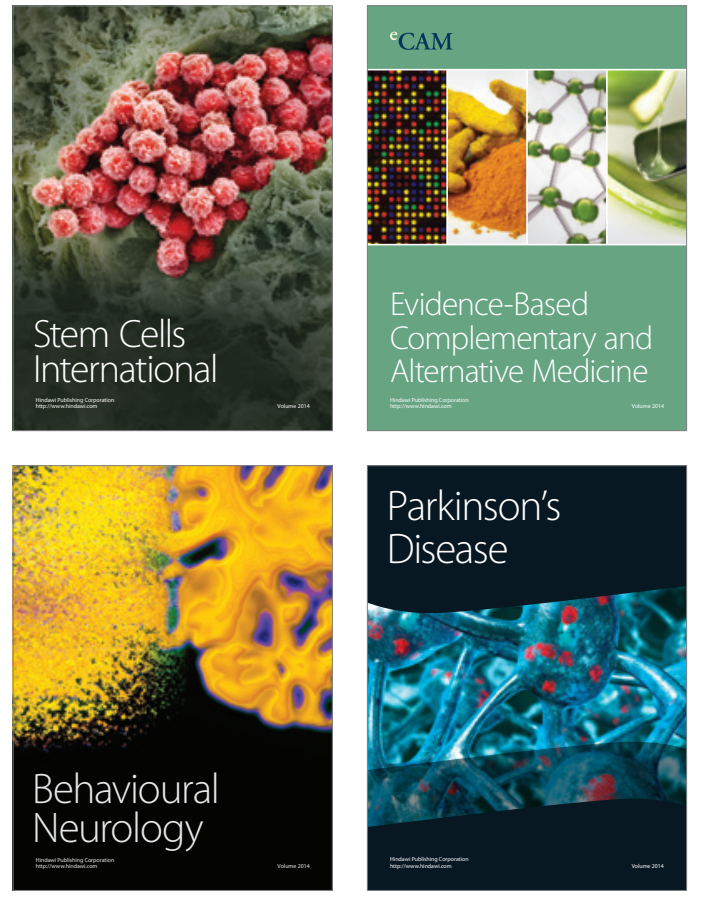
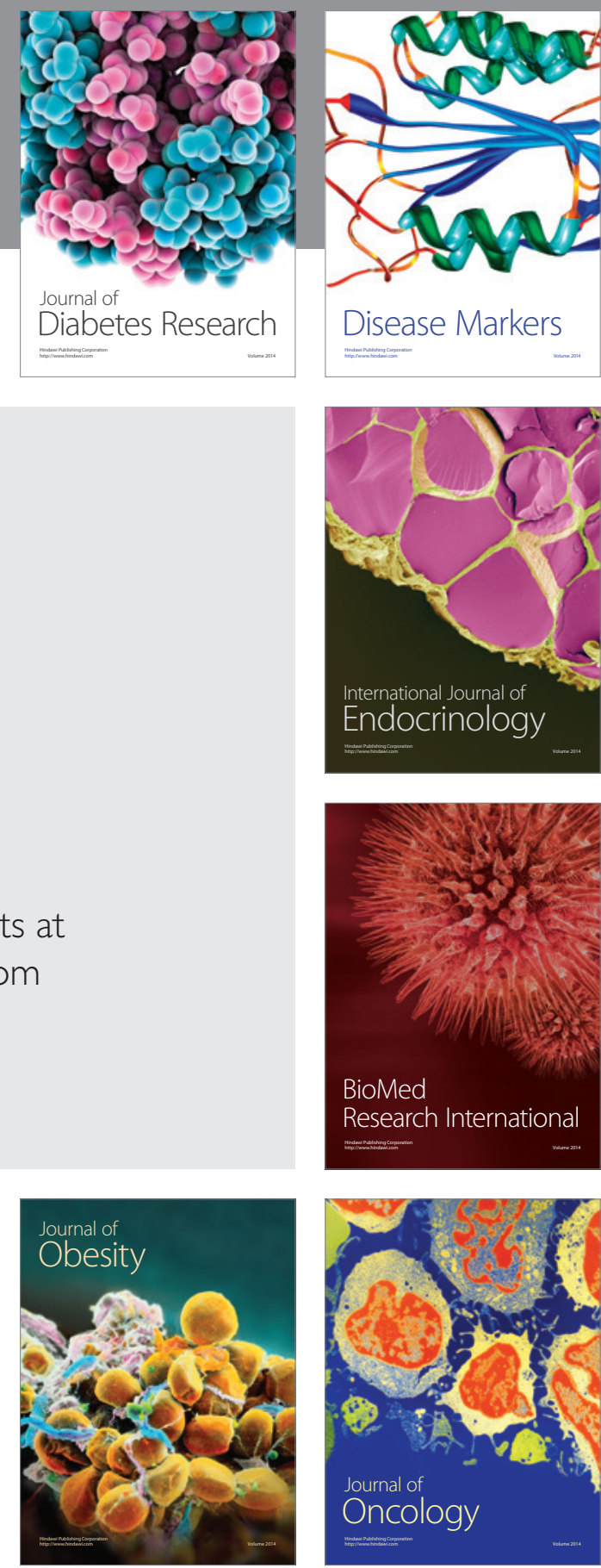

Disease Markers
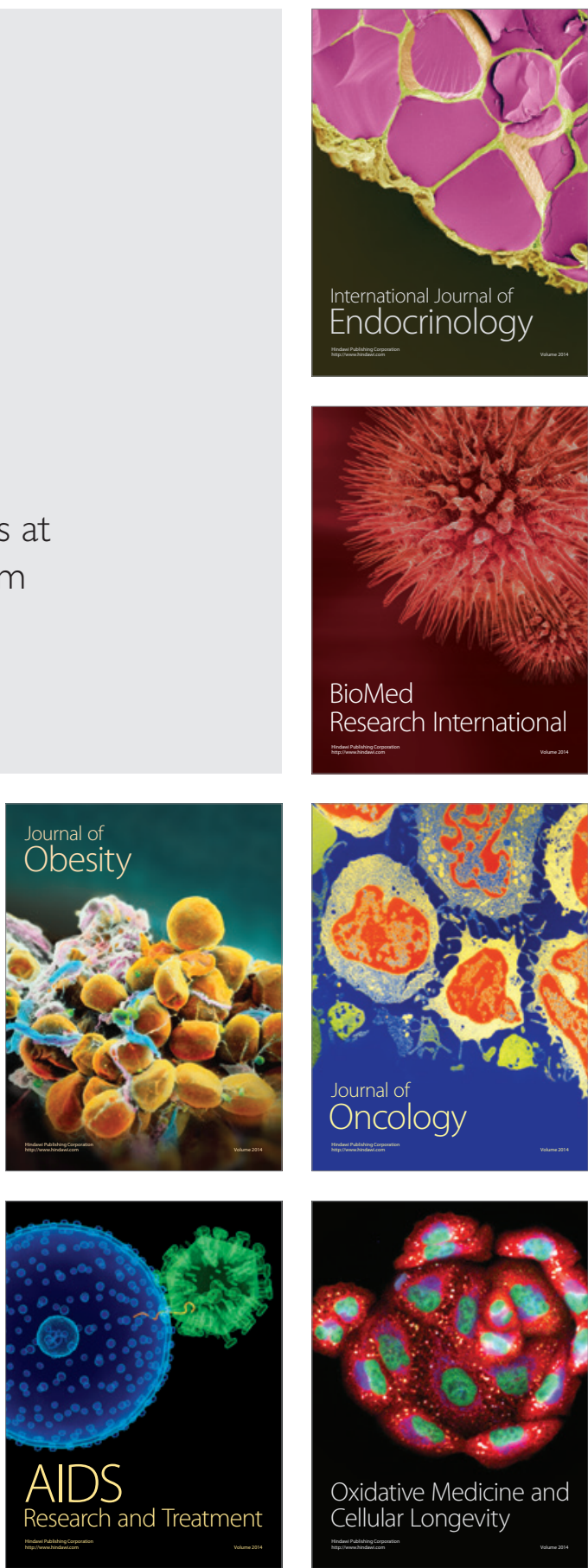